\title{
THE
}

\section{Crustal and mantle velocity models of southern Tibet from finite frequency tomography}

\author{
Xiaofeng Liang \\ Yang Shen \\ University of Rhode Island, yshen@uri.edu \\ Yongshun John Chen \\ Yong Ren \\ University of Rhode Island
}

Follow this and additional works at: https://digitalcommons.uri.edu/gsofacpubs

Terms of Use

All rights reserved under copyright.

\section{Citation/Publisher Attribution}

Liang, X., Y. Shen, Y. J. Chen, and Y. Ren (2011), Crustal and mantle velocity models of southern Tibet from finite frequency tomography, J. Geophys. Res., 116, B02408, doi: 10.1029/2009JB007159.

Available at: https://doi.org/10.1029/2009JB007159

This Article is brought to you for free and open access by the Graduate School of Oceanography at DigitalCommons@URI. It has been accepted for inclusion in Graduate School of Oceanography Faculty Publications by an authorized administrator of DigitalCommons@URI. For more information, please contact digitalcommons-group@uri.edu. 


\title{
Crustal and mantle velocity models of southern Tibet from finite frequency tomography
}

\author{
Xiaofeng Liang, ${ }^{1}$ Yang Shen, ${ }^{2}$ Yongshun John Chen, ${ }^{1}$ and Yong Ren ${ }^{2}$ \\ Received 21 November 2009; revised 25 October 2010; accepted 22 November 2010; published 15 February 2011.
}

[1] Using traveltimes of teleseismic body waves recorded by several temporary local seismic arrays, we carried out finite-frequency tomographic inversions to image the threedimensional velocity structure beneath southern Tibet to examine the roles of the upper mantle in the formation of the Tibetan Plateau. The results reveal a region of relatively high $P$ and $S$ wave velocity anomalies extending from the uppermost mantle to at least $200 \mathrm{~km}$ depth beneath the Higher Himalaya. We interpret this high-velocity anomaly as the underthrusting Indian mantle lithosphere. There is a strong low $P$ and $S$ wave velocity anomaly that extends from the lower crust to at least $200 \mathrm{~km}$ depth beneath the Yadong-Gulu rift, suggesting that rifting in southern Tibet is probably a process that involves the entire lithosphere. Intermediate-depth earthquakes in southern Tibet are located at the top of an anomalous feature in the mantle with a low $\mathrm{Vp}$, a high $\mathrm{Vs}$, and a low $\mathrm{Vp} / \mathrm{Vs}$ ratio. One possible explanation for this unusual velocity anomaly is the ongoing granulite-eclogite transformation. Together with the compressional stress from the collision, eclogitization and the associated negative buoyancy force offer a plausible mechanism that causes the subduction of the Indian mantle lithosphere beneath the Higher Himalaya. Our tomographic model and the observation of north-dipping lineations in the upper mantle suggest that the Indian mantle lithosphere has been broken laterally in the direction perpendicular to the convergence beneath the north-south trending rifts and subducted in a progressive, piecewise and subparallel fashion with the current one beneath the Higher Himalaya.

Citation: Liang, X., Y. Shen, Y. J. Chen, and Y. Ren (2011), Crustal and mantle velocity models of southern Tibet from finite frequency tomography, J. Geophys. Res., 116, B02408, doi:10.1029/2009JB007159.

\section{Introduction}

[2] The unique role of the Himalayan range and Tibetan Plateau in understanding continent-continent collision has led to numerous geological and geophysical studies in the region, including several temporary seismic networks operated from the southern Himalaya in Nepal to the Lhasa Terrane of southern Tibet in China during the past two decades [e.g., Hirn et al., 1995; Nelson et al., 1996; de la Torre and Sheehan, 2005; Nabelek et al., 2005; Sol et al., 2007; Velasco et al., 2007]. Yet questions remain about the crust and upper mantle structures, particularly variations in the direction perpendicular to the India-Eurasia convergence, and their implications for the history and dynamics of the Himalaya and the plateau.

[3] Since the work of Argand [1924], the nature and extent of the underthrusting of the Indian lithosphere under the Tibetan Plateau has been a topic of debate [e.g., Willett and Beaumont, 1994]. Several studies suggest that the Tibetan

\footnotetext{
${ }^{1}$ Institute of Theoretical and Applied Geophysics, School of Earth and Space Sciences, Peking University, Beijing, China.

${ }^{2}$ Graduate School of Oceanography, University of Rhode Island, Kingston, Rhode Island, USA.

Copyright 2011 by the American Geophysical Union. 0148-0227/11/2009JB007159
}

Plateau south of the Bangong-Nujiang suture (Figure 1a) is underlain by the Indian lithosphere. This interpretation is based on high $P n$ and $S n$ velocities [Ni and Barazangi, 1984], gravity anomalies [Jin et al., 1996], seismic converted phases [Owens and Zandt, 1997], SKS splitting [Fu et al., 2008] and tomographic results [Tilmann et al., 2003; Zhou and Murphy, 2005]. Receiver function studies also reveal a doublet phase in the Tibetan crust, which was interpreted as evidence for the underthrusting Indian lower crust beyond the Indus-Yalu suture (IYS) [Kind et al., 2002; Nabelek et al., 2005; SchultePelkum et al., 2005; Jin et al., 2006; Nabelek et al., 2009]. However, receiver functions [Kosarev et al., 1999] and Helium isotope ratios [Hoke et al., 2000] show evidence that the Indian mantle lithosphere starts subduction near the IYS. A recent study of $S$-to- $P$ converted phases in the western Tibetan Plateau [Kumar et al., 2006] and body wave tomography [Li et al., 2008] suggest that the geometry of the Indian lithosphere varies from west to east: Underthrusting beneath the Himalayas and the entire plateau in the west and subducting at an angle in the east.

[4] There are two other enigmatic geological features in southern Tibet: The north-south trending rifts [e.g., Armijo et al., 1986] and the intermediate-depth earthquakes [Chen et al., 1981; Chen and Molnar, 1983; Zhu and Helmberger, 1996; Chen and Yang, 2004; Monsalve et al., 2006; Liang 
a.

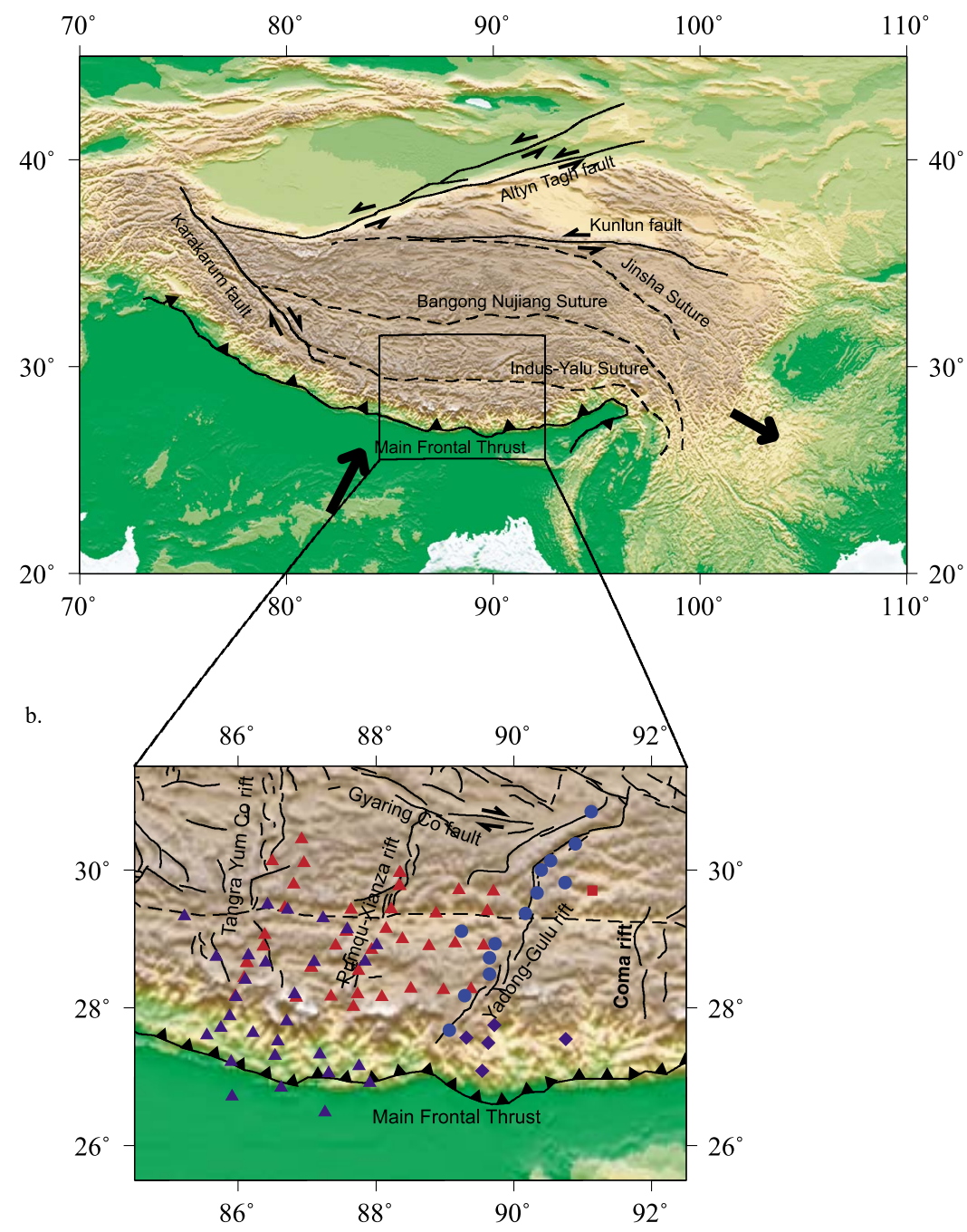

Figure 1. (a) Tectonic map of the Tibetan Plateau with the research area of this study outlined by a box. The directions of plate movement are from Zhang et al. [2004]. (b) Map of our study area showing active faults and seismic stations used in this study. The stations from different sources are denoted in different symbols: Hi-CLIMB as red triangles, HIMNT as blue triangles, Bhutan as blue diamond, INDEPTH II (International Deep Profiling of Tibet and the Himalaya) as blue circles, and LSA as red square.

et al., 2008]. The rifts are commonly attributed to the eastwest extension of southern Tibet, which is roughly perpendicular to the India-Eurasia convergence direction [Larson et al., 1999]. Several mechanisms have been proposed for these rifts, including gravitational collapse following the attainment of the maximum elevation [Molnar and Tapponnier, 1978; Tapponnier et al., 1981], lower crust flow under east-west extension, oblique convergence of Indian subduction [McCaffrey and Nabelek, 1998], lithosphere fragmentation accompanied with the regional boundary condition applied throughout East Asia [Yin, 2000], and deformation facilitated by mantle lithosphere delamination [Ren and Shen, 2008]. Whether these rifts are restricted to the upper crust or involve the entire lithosphere has also been under debate [Masek et al., 1994; Yin, 2000]. Ren and Shen [2008] found a significant low Vp and Vs anomaly extending to $350 \mathrm{~km}$ depth beneath the Coma rift, one of the northsouth trending rifts near the East Syntaxis, and suggested that the rift could be related to a mantle lithosphere delamination process.

[5] The intermediate-depth earthquakes beneath southern Tibet have been interpreted to be caused by the "sandwich" rheology structure of the Tibetan lithosphere [Chen and Molnar, 1983]. The "sandwich" rheology structure divides the continental lithosphere into two seismogenic layers: The upper crust and the uppermost mantle, which are separated by a ductile/weaker lower crust. This concept has been used to construct numerical models of the Tibetan Plateau [e.g., Zhao and Morgan, 1985, 1987] and to interpret the geophysical observations from the INDEPTH projects (International Deep Profiling of Tibet and the Himalaya) in southern Tibet. For example, the bright spots in the INDEPTH seismic reflection profiles and a low electromagnetic resistance layer in the middle crust were presented as supporting evidence for the existence of a ductile lower crust in Tibet [Brown et al., 1996; Chen et al., 1996]. This model was recently challenged by 


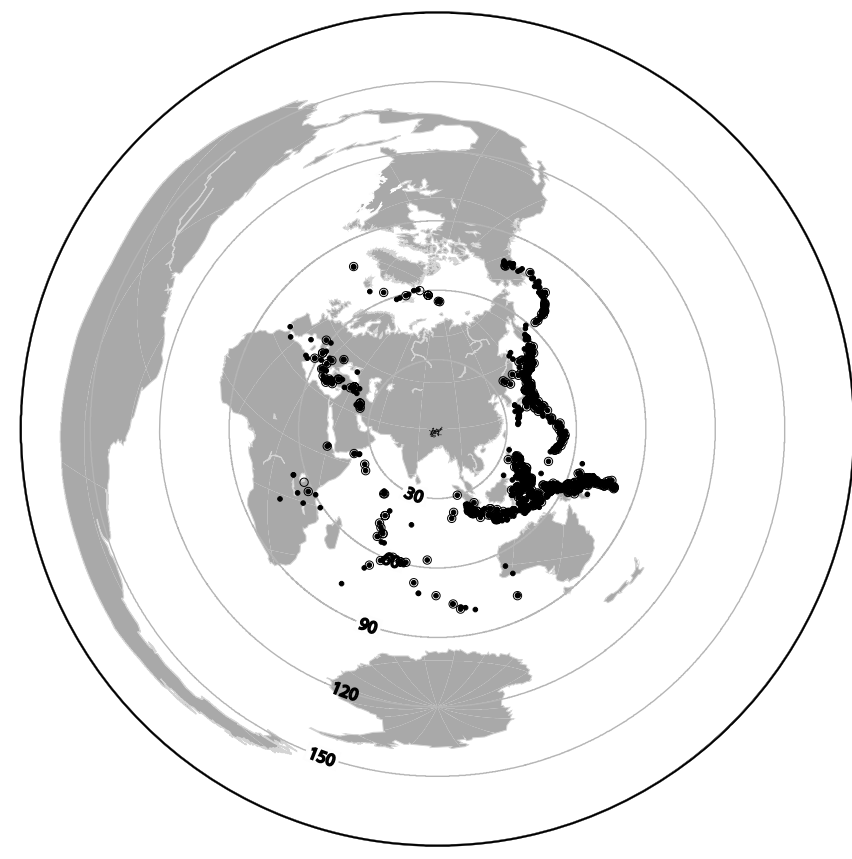

Figure 2. Earthquakes used in the inversion shown as black circles at epicentral distance of $30^{\circ}-80^{\circ}$. Open circles represent the events with measured $S$ wave traveltimes, and solid circles are those providing $P$ wave data.

Jackson [2002] and Jackson et al. [2004], who argued that there is just one seismogenic layer within the crust for the continental lithosphere and the intermediate-depth earthquakes could be the result of the transition from granulite to eclogite [Jackson et al., 2004]. Priestley et al. [2008] suggested that those earthquakes are due to stress concentration induced by the bending of the cold Indian lithosphere in a "ramp and flat" shape of the Moho.

[6] In this study we combine data from the Hi-CLIMB [Nabelek et al., 2005], INDEPTH [Nelson et al., 1996], BHUTAN [Velasco et al., 2007], and HIMNT [de la Torre and Sheehan, 2005] projects and apply the finite frequency traveltime tomography method to image the velocity structure beneath southern Tibet (Figure 1b). The resulting threedimensional (3-D) crustal and upper mantle velocity models of the Himalayas and the southern Lhasa Terrane provide new insights into the extent of the underthrusting Indian lithosphere, the origin of the north-south trending rifts, and the cause of the intermediate-depth seismicity in southern Tibet.

\section{Tectonics Setting}

[7] The main Cenozoic structures in southern Tibet include the north-south trending rifts and the WNW-trending rightslip faults (Figure 1b) [Armijo et al., 1986, 1989]. The Main Frontal Thrust (MFT) along the Himalaya marks the southern edge of the Himalayan Range. The north-south trending rifts in the study area are, from east to west, the Yadong Gulu rift (YGR), the Pumqu Xianza rift (PXR), and the Tangra Yum Co rift (TYR) (Figure 1b). The northern ends of the TYR and PXR are connected by the Gyaring Co fault, which is a WNW-trending right-lateral slip fault and belongs to the Central Tibet conjugate fault zone [Taylor et al., 2003]. This fault zone has been suggested as a transfer zone linking northsouth trending Cenozoic extensional structures in the Lhasa and Qiangtang Terranes [Yin and Harrison, 2000].

[8] Here we adopt the definition of Yin [2006] that the IYS divides the Himalayan orogen to the south and the Tibetan Plateau to the north. We further refer to the crest of the Himalayan orogen as the Higher Himalaya, its north slope as the North Himalaya, and its south slope as the South Himalaya, which in turn consists of the Lower Himalaya in the north and the Sub Himalaya in the south. Our study area traverses the boundary between the Himalayan orogen and the Tibet Plateau. For convenience, southern Tibet is used in this paper to describe the general location of our study region, including the southern Tibetan Plateau and the Himalayas.

\section{Data}

[9] Data used in this study are from several seismic projects in southern Tibet: Hi-CLIMB, HIMNT, BHUTAN and INDEPTH II. The combined data set includes 80 stations: 32 from Hi-CLIMB, 29 from HIMNT, 1 from the Global Seismic Network, 5 from BHUTAN, and 13 from INDEPTH II (Figure 1b). Among these, 16 of the 32 stations in the HiCLIMB two-dimensional (2-D) network were operated by Peking University during 2004 and 2005 as a part of the HiCLIMB project. The remaining stations in the Hi-CLIMB 2-D array were operated by the Institute of Earth Sciences, Academia Sinica, Taiwan and China Academy of Geological Sciences.

[10] Teleseismic $P$ and $S$ phases were used in our tomographic inversion. We selected events with an epicentral distance between $30^{\circ}-80^{\circ}$ to minimize the interference of long-period waves from the mantle transition zone and coremantle boundary (Figure 2). The raw data were first converted to displacement by removing instrument response. For $S$ wave the waveforms were rotated to the radial and tangential directions. Then, the waveforms were filtered to two frequency bands: $0.5-2 \mathrm{~Hz}$ and $0.1-0.5 \mathrm{~Hz}$ for $P$ wave, and $0.1-0.5 \mathrm{~Hz}$ and $0.05-0.1 \mathrm{~Hz}$ for $S$ wave, using the Butterworth filter with four poles and two passes. We first handpicked the arrival times of the phases then obtained the differential traveltimes by the Multiple Channel Cross Correlation method (MCCC) [VanDecar and Crosson, 1990]. The cross-correlation time window is usually a full wave period containing the largest absolute amplitude of the arrival. The traveltimes used in the inversion are 11137 high-frequency and 4121 low-frequency $P$ waves, and 1850 high-frequency and 1233 low-frequency $S$ waves.

\section{Method}

[11] In this study, a finite-frequency seismic tomographic method was used to invert for the $P$ and $S$ wave crustal and upper mantle velocity structures beneath southern Tibet. The inversion method was described in details by Hung et al. [2004], Yang and Shen [2006] and Ren and Shen [2008]. Here we present a simplified description of the method.

\subsection{Finite Frequency Theory}

[12] The Born-Fréchet traveltime sensitivity kernels express the influence of velocity perturbations upon a travel 


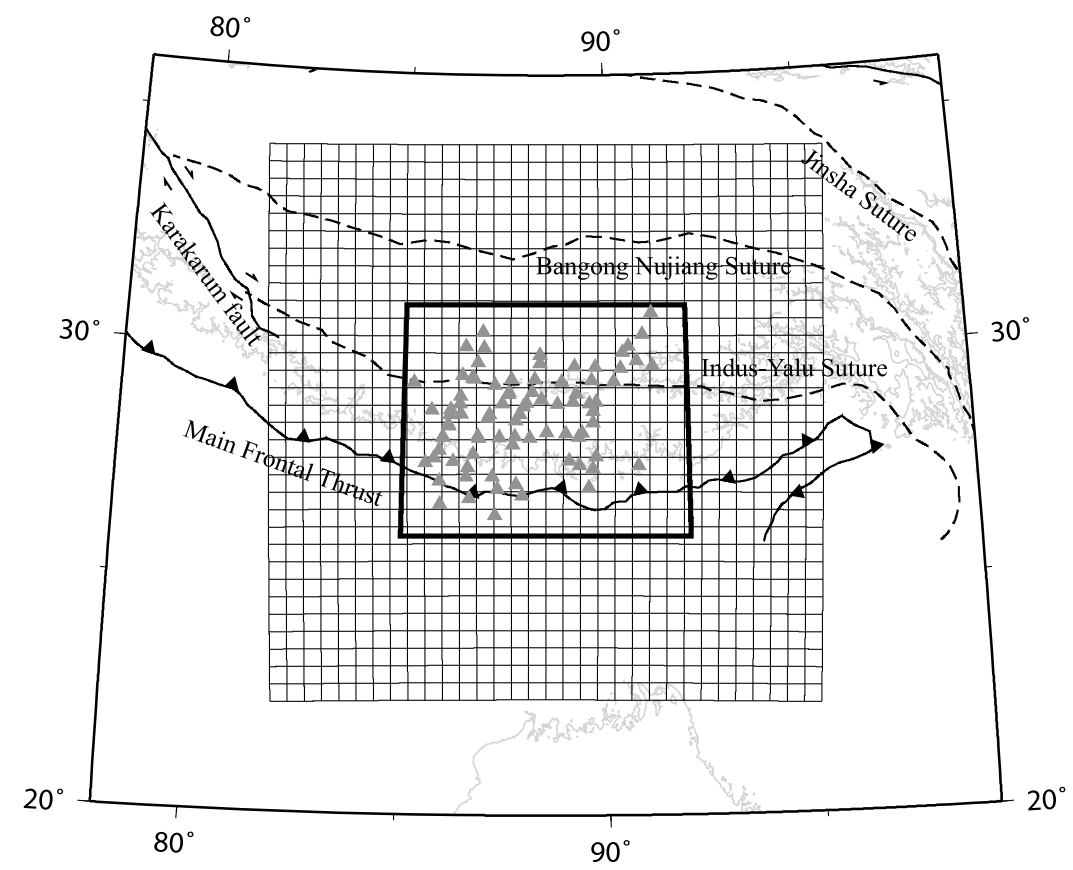

Figure 3. Model space is shown as the gray mesh, and the black rectangle shows the research area displayed in the following figures. Stations are shown as gray triangles. The $4000 \mathrm{~m}$ elevation contour line is shown as gray lines.

time shift of finite-frequency waves as [Dahlen et al., 2000]:

$$
\delta t=\iiint_{\oplus} K(x) \delta c(x) / c(x) d^{3} x
$$

where $K$ is the 3-D Fréchet sensitivity kernel for a travel time shift $\delta t$, measured by cross correlation of an observed pulse with its synthetics for a reference earth model. Under the assumption of single scattering, the kernel is expressed by the formulation [Dahlen et al., 2000]:

$$
K=\frac{1}{2 \pi c}\left(\frac{R}{c_{r} R^{\prime} R^{\prime \prime}}\right) \times \frac{\int_{0}^{\infty} \omega^{3}\left|s_{\text {syn }}(\omega)\right|^{2} \sin (\omega \Delta T) d \omega}{\int_{0}^{\infty} \omega^{2}\left|s_{s y n}(\omega)\right|^{2} d \omega},
$$

where $\Delta T$ represent the difference in travel time between the path with a detour through a scatterer between the source and receiver relative to the corresponding direct path; $R, R^{\prime}$ and $R^{\prime \prime}$ are geometrical spreading factors for the unperturbed ray, the forward source-to-scatterer ray and the backward receiver-to-scatterer ray, respectively. The presence of the power spectrum of the synthetic pulse $\left|s_{s y n}\right|^{2}$ shows effectively the frequency dependence of the cross-correlated differential travel times.

[13] For regional teleseismic travel time tomography the relative arrival times of $P$ or $S$ phases at a number of stations are measured by MCCC to constrain spatial variations of underlying mantle velocity perturbations. The finite volume sensitivity of a relative delay between two nearby stations 1 and $2, \delta t_{1}-\delta t_{2}$, is simply the difference of the individual Fréchet kernels for the traveltime shifts, $\delta t_{1}$ and $\delta t_{2}$ [Dahlen et al., 2000; Hung et al., 2004],

$$
K_{\delta t_{1}-\delta t_{2}}=K_{\delta t_{1}}-K_{\delta t_{2}}
$$

\subsection{Model Parameterization and Inversion}

[14] The crustal and mantle volume beneath the study area was parameterized with regular 3 -D grids of $33 \times 33 \times$ 33 centered at $\left(88.5^{\circ} \mathrm{E}, 28.5^{\circ} \mathrm{N}\right)$ with total dimensions of $12^{\circ}$ in longitude, $12^{\circ}$ in latitude, and $1200 \mathrm{~km}$ in depth (Figure 3). That is, the grid spacing is $\sim 0.37^{\circ}$ in longitude and latitude and $\sim 37 \mathrm{~km}$ in depth. With this parameterization, the traveltime equations can be written as:

$$
d_{i}=G_{i l} m_{l}
$$

where $d_{i}$ is the $i$ th travel time data, and $G_{i l}$ is the differential value of the integrated volumetric kernels of the $i$ th event contributing to the $l$ th node and $m_{l}$, the model parameter at the $l$ th node. The inversion problem was resolved by the standard damped least square method [Paige and Saunders, 1982]:

$$
\hat{m}=\left(G^{T} G+\theta^{2} I\right)^{-1} G^{T} d
$$

where $\boldsymbol{I}$ is the identity matrix. The damping parameter $\theta$ is determined empirically through a space of variance reduction and the model norm represented by a trade-off curve (Figure 4). We chose the damping parameter that yields an optimum variance reduction and a relatively small model norm. The model discussed in this paper is obtained using a damping parameter that yields a variance reduction of $\sim 76 \%$ for $P$ wave and $\sim 57 \%$ for $S$ wave (shown as a filled square and filled circle, respectively, in Figure 4). The lower variance reduction of the $S$ velocity model reflects relatively noisy $S$ waves and $S$ traveltime measurements.

\subsection{Crustal and Elevation Correction}

[15] The traveltime anomalies can be caused by crustal thickness variations, station elevations and lateral velocity 


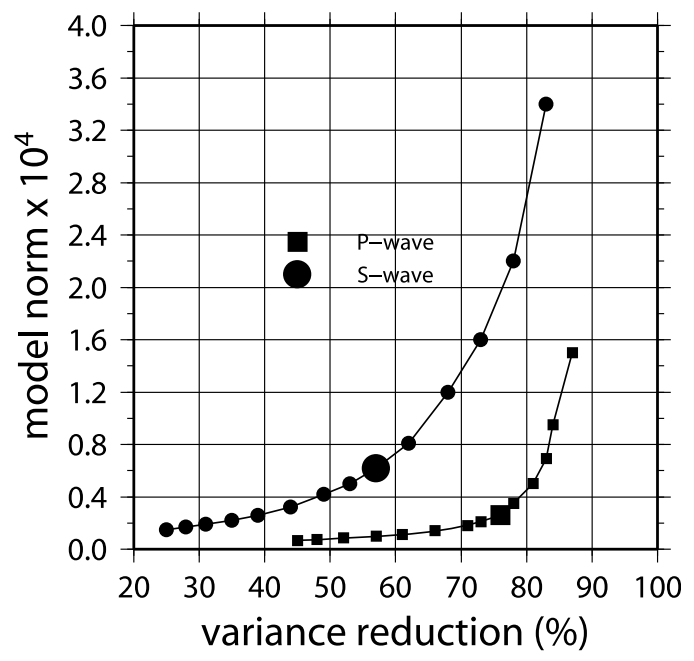

Figure 4. Tradeoff curves for $P$ wave and $S$ wave inversions. The larger symbols represent the preferred models discussed in the interpretations.

heterogeneities. Since the ray paths of teleseismic body waves are nearly vertical and do not cross at shallow depth, shallow velocity structures are poorly constrained by relative traveltime data in the inversion. Therefore, a time correction for crustal structure is needed in order to reduce the tradeoff between crustal and mantle velocity heterogeneities in seismic tomography. To correct for the crustal effects, the frequency dependant crustal correction for each event station record was calculated from the synthetic crustal response of an incoming plane wave beneath the station [Yang and Shen, 2006]. We used the crustal structure from the CRUST2.0 [Bassin et al., 2000] for stations in Sub Himalaya and SEAPS [Sun et al., 2004; Sun et al., 2008] for stations elsewhere. An additional free term for each station was incorporated into the inversion to absorb traveltime shifts caused by remaining shallow heterogeneity.

\subsection{Vp/Vs Ratio Perturbation}

[16] Because the relative travel time of one phase recorded at two stations is used to constrain the underlying mantle velocity perturbation, the inversion solves spatial distribution of relative velocity perturbation but does not provide constraints on the absolute velocity perturbation. Given a 1-D reference model for the study area, the perturbation of $\mathrm{Vp} / \mathrm{Vs}$ ratio $(\delta r)$ can be retrieved from $\mathrm{Vp}$ and Vs perturbations in percentage $\delta \mathrm{Vp}$ and $\delta \mathrm{Vs}$, respectively,

$\delta r=\frac{r_{\text {inverted }}-r_{\text {reference }}}{r_{\text {reference }}}=\left(\frac{\left(1+\delta V_{p}\right) V_{p}}{\left(1+\delta V_{s}\right) V_{s}}-\frac{V_{p}}{V_{s}}\right) / \frac{V_{p}}{V_{s}}=\frac{\delta V_{p}-\delta V_{s}}{1+\delta V_{s}}$.

Several different approaches have been used to calculate $\mathrm{Vp} / \mathrm{Vs}$ tomographic models. With good ray coverage for both
$P$ and $S$ waves, the $\mathrm{Vp} / \mathrm{Vs}$ could be calculated directly from separate Vp and Vs models [Nakajima et al., 2001; Nakamura et al., 2003]. When either the $S$ wave data coverage is not good or there is significant difference in the data coverage for $P$ and $S$ waves, mapping $\mathrm{Vp} / \mathrm{Vs}$ using separate $\mathrm{Vp}$ and Vs solutions is inappropriate [Eberhart-Phillips, 1990]. A simultaneous inversion for $\mathrm{Vp}$ and $\mathrm{Vp} / \mathrm{Vs}$ ratio without the assumption of identical $P$ and $S$ coverage should be used [Conder and Wiens, 2006].

[17] In our case with a significant difference in $P$ and $S$ data coverage, artificial features in the $\mathrm{Vp} / \mathrm{Vs}$ models could be present when structures are resolved only in the $P$ or $S$ inversion [Kennett et al., 1998; Saltzer et al., 2004]. To minimize artificial features in $\mathrm{Vp} / \mathrm{Vs}$ ratio introduced from independent Vp or Vs inversions, we selected $P$ and $S$ travel times with the objective of finding a subset of the $P$ and $S$ data that have the same data coverage. This results in the use of 1179 low-frequency $P$ phase travel times and the same number of high-frequency $S$ phase relative travel times that share nearly identical source-receiver paths. Consequently, the $\mathrm{Vp}$ and $\mathrm{Vs}$ perturbations used for the calculation of $\mathrm{Vp} / \mathrm{Vs}$ were inverted with the same inversion parameters, since the selected $P$ and $S$ travel times have a very similar sensitivity kernel distribution.

[18] The difference in $\mathrm{Vp} / \mathrm{Vs}$ ratio among different 1-D reference velocity models is small compared to the range of values observed in the study area in the lower crust and upper mantle depths. For example, the maximum difference of $\mathrm{Vp} / \mathrm{Vs}$ ratio between IASP91 and AK135 is $0.2 \%$ from $35 \mathrm{~km}$ to $660 \mathrm{~km}$ depth.

\subsection{Resolution Tests}

[19] Horizontal and vertical resolution tests were performed to evaluate the data coverage and the ability of the inversion to recover the mantle structure (Figure 5). For this purpose, the synthetic traveltimes were computed by multiplying the $G$ matrix with different input velocity models: $\Delta \boldsymbol{t}_{\text {syn }}=\boldsymbol{G} \cdot \Delta \boldsymbol{c}_{\text {syn }}+\boldsymbol{t}_{\text {noise }}$, where $\boldsymbol{t}_{\text {noise }}$ is random noise added to the synthetic traveltimes with a Gaussian distribution and the standard deviation of $\boldsymbol{t}_{\text {noise }}$ is set to 0.04 second and 0.1 second for $P$ and $S$ resolution tests shown in Figure 5. The inversion was then performed using the same damping parameter as that used in the inversion of real data. In the first set of tests, which evaluate the horizontal resolution, the checkerboard resolution tests were conducted using input anomalies with a horizontal scale of $150 \mathrm{~km}$ or $100 \mathrm{~km}$. The magnitude of the velocity perturbation decreases from the center of the checkerboard cells to zero at the boundaries (using a cosine taper). The maximum velocity perturbation is $\pm 2 \%$ for $P$ wave and $\pm 4 \%$ for $S$ wave, respectively. We calculated the correlation coefficients and the differences of the input and output models at various depths. With the criteria of the correlation coefficient higher than $85 \%$ and the input-output difference less than $25 \%$ of the input anomaly, we estimated that the recovered structure meets the criteria

Figure 5. The input and output velocity models are shown in the left and middle columns at three different cross sections along the north-south direction ( $\left.\mathrm{AA}^{\prime}\right)$, east-west direction $\left(\mathrm{CC}^{\prime}\right)$, and direction perpendicular to the Yadong-Gulu rift $\left(\mathrm{BB}^{\prime}\right)$. The locations of these three profiles are shown in the map in the upper left corner. The 3-D input-output correlation coefficients are shown in the right column for both Vp (upper three rows) and Vs (lower three rows) models, and the regions with correlation coefficient greater than $85 \%$ are enclosed by black contour lines. 

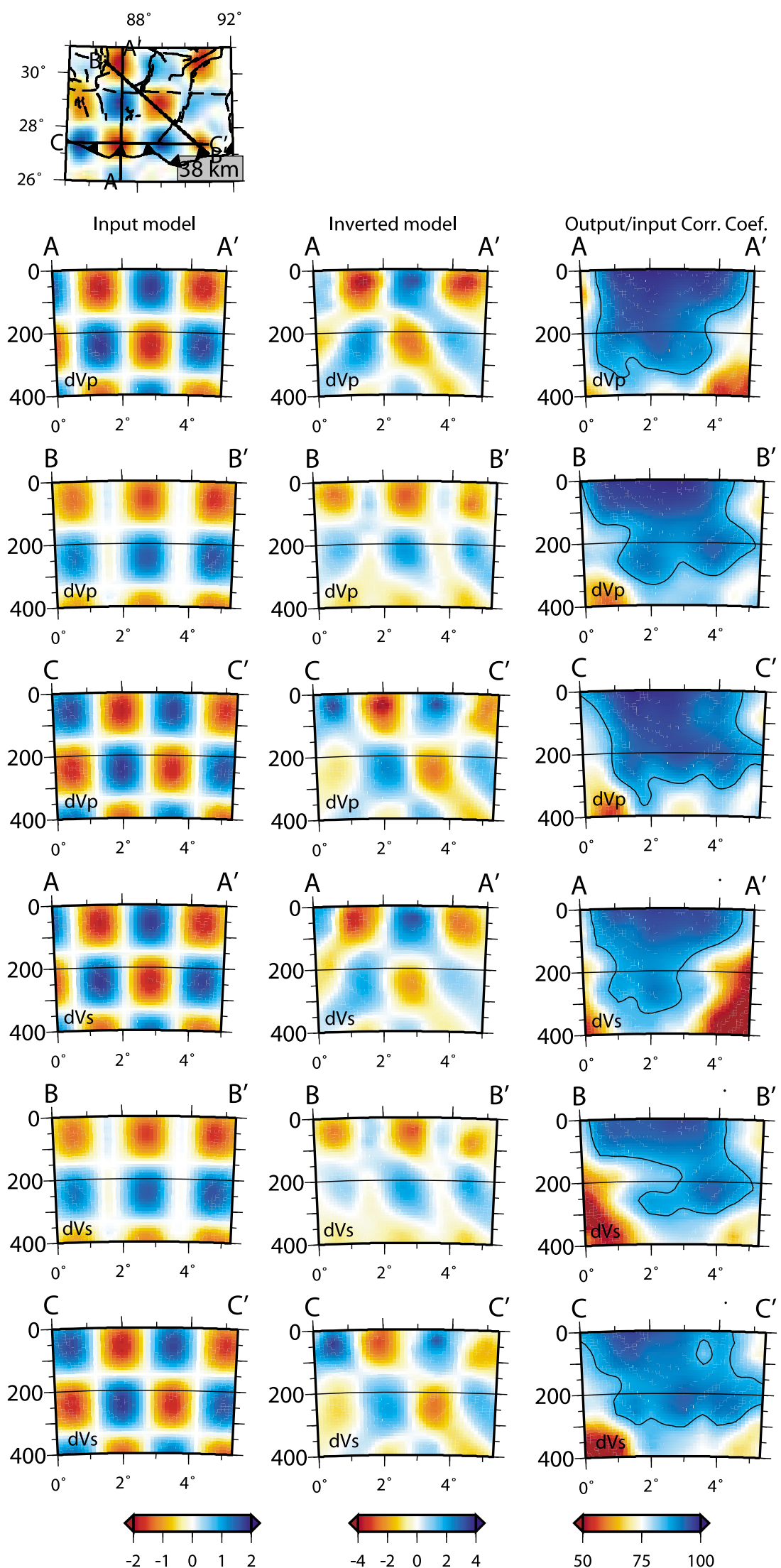

P-wave velocity (\%)

S-wave velocity (\%)

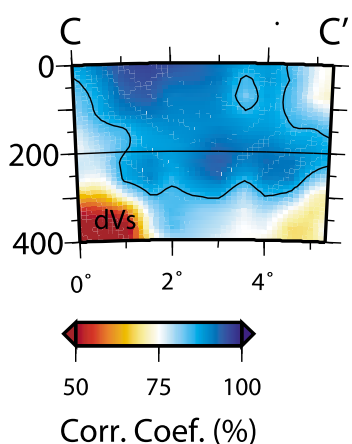

Figure 5 
down to $\sim 350 \mathrm{~km}$ depth for $P$ wave models and $\sim 200 \mathrm{~km}$ depth for $S$ wave models. The resolution also worsens in shallow depth $(<50 \mathrm{~km})$, particularly for $S$ waves. The horizontal scales of the interpreted features in our tomographic models are about $150 \mathrm{~km}$ or larger.

[20] In the second set of tests, for both horizontal and vertical resolution, the input velocity perturbation alternates in sign both horizontally and vertically (Figure 5). Threedimensional correlation coefficients were calculated for these tests. Within the $33 \times 33 \times 33$ inversion grid, a moving cube with $5 \times 5 \times 5$ grids in both the input and output models was selected and interpolated, then cross-correlation coefficient was calculated between these two cubes as the correlation coefficient for the central grid of the cube. In the center of the models, the 3-D correlation coefficient is greater than $85 \%$ to $300 \mathrm{~km}$ depth for $\mathrm{Vp}$ and to $200 \mathrm{~km}$ depth for Vs. Thus in the following discussion we interpret the $P$ wave model in the upper $300 \mathrm{~km}$ depth and the $S$ wave model in the upper $200 \mathrm{~km}$ depth.

[21] For the $\mathrm{Vp} / \mathrm{Vs}$ resolution (Figure 5), separate $\mathrm{Vp}$ and Vs inversions are carried out using $1179 P$ and $1179 S$ traveltimes that have nearly identical ray paths.

[22] We also carried out tests with different levels of $\boldsymbol{t}_{\text {noise }}$ and found that the results are quite similar for the noise level smaller than 0.3 second.

\subsection{Null-Space Shuttle Method}

[23] We used the null-space shuttle method [Deal and Nolet, 1996; Muñoz and Rath, 2006] to test the robustness of the low $\mathrm{Vp} / \mathrm{Vs}$ anomaly in our final result. The null-space shuttle method is an approach to determine the permissible changes for a tomographic image while retaining the fit to the data [Deal and Nolet, 1996; Muñoz and Rath, 2006]. For our inversion problem:

$$
\boldsymbol{d}=\boldsymbol{G m}
$$

the original inverted model $\boldsymbol{m}$ can be modified to get a filtered solution $\boldsymbol{m}_{f}$. The difference between them is $\Delta \boldsymbol{m}=\boldsymbol{m}_{f}-\boldsymbol{m}$. With the requirement that $\Delta \boldsymbol{m}=\Delta \boldsymbol{m}_{\text {range }}-\Delta \boldsymbol{m}_{\text {null }}$ and the assumption of and $\boldsymbol{G} \Delta \boldsymbol{m}_{\text {null }}=\mathbf{0}$, where $\Delta \boldsymbol{m}_{\text {range }}$ is the model space with good data coverage and $\Delta \boldsymbol{m}_{\text {null }}$ is the portion of the model space in the null-space, the linear inversion problem could be expressed as,

$$
\boldsymbol{G} \Delta \boldsymbol{m}=\boldsymbol{G} \Delta \boldsymbol{m}_{\text {range }}=\Delta \boldsymbol{d} .
$$

Where the $\Delta \boldsymbol{d}$ is the difference between the original data $\boldsymbol{d}$ and the data corresponding to the filtered model $\boldsymbol{m}_{f}$, which are the traveltime residuals only related with the model difference $\Delta \boldsymbol{m}_{\text {range }}$ with good data coverage. This equation could be solved just like equation (7) by the standard damped least square method, and the final conservatively filtered solution is

$$
\boldsymbol{m}_{\text {consv }}=\boldsymbol{m}_{f}-\Delta \boldsymbol{m}_{\text {range }} .
$$

\section{Results}

[24] The resulting three-dimensional $P$ and $S$ wave velocity models from all the usable $P$ and $S$ traveltimes and the $\mathrm{Vp} / \mathrm{Vs}$ ratio from the selected $P$ and $S$ data that share nearly identical paths are presented in Figures $6 \mathrm{a}$ and $6 \mathrm{~b}$. Because we used differential traveltime in this teleseismic tomography, the absolute velocity perturbation could not be constrained. The fast or slow velocity anomalies discussed here are all relative anomalies.

[25] The most prominent feature in these 3-D velocity models is a high $\mathrm{Vp}$ and Vs anomaly along the strike of Higher Himalaya that extends from the surface to about $180 \mathrm{~km}$ depth. This high-velocity anomaly is attributed to the Indian mantle lithosphere. To the north of this highvelocity anomaly there are strong low-velocity anomalies at about $75 \mathrm{~km}$ depth beneath the North Himalaya, which likely reflect the velocity difference between the thickened Tibetan crust and the cold Indian mantle lithosphere.

[26] In the uppermost mantle, there is a strong low $\mathrm{Vp}$ and Vs anomaly with a small positive $\mathrm{Vp} / \mathrm{Vs}$ ratio perturbation extending to $\sim 200 \mathrm{~km}$ depth (Figures 6a, 6b, and 7) along the YGR. A less pronounced low-velocity anomaly is present beneath the TYR. These are similar to the low-velocity anomaly along the Coma rift east of our study area close to the Eastern Syntaxis [Ren and Shen, 2008].

[27] At the depth of about $75 \mathrm{~km}$, there is a low $\mathrm{Vp} / \mathrm{Vs}$ ratio in the region between the MFT and the southern ends of the PXR and TYR (Figures 6a, 6b, and 9). This low Vp/Vs region coincides with a cluster of the hypocenters of the intermediate-depth earthquakes in southern Tibet [Monsalve et al., 2006; Liang et al., 2008]. We used the null-space shuttle method [Deal and Nolet, 1996; Muñoz and Rath, 2006] to test the robustness of this low $\mathrm{Vp} / \mathrm{Vs}$ anomaly. In the test the $\mathrm{Vp} /$ Vs perturbation result is obtained from the selected $P$ and $S$ data set with nearly identical paths. The best-fitting inverted models were filtered to remove the low $\mathrm{Vp} / \mathrm{Vs}$ anomaly at the south end of the PXR (shown in the second column in Figure 9). Then the null-space shuttle method was applied to the filtered models and the conservatively filtered models were retrieved. The $\mathrm{Vp} / \mathrm{Vs}$ ratio anomaly near the center of the model was recovered, suggesting that the low $\mathrm{Vp} / \mathrm{Vs}$ anomaly at the southern end of the PXR is not part of the nullspace but is indeed required by the data.

\section{Discussion}

\subsection{Influence From Crust Structures}

[28] We use teleseismic traveltimes to invert the regional structures in the crust and upper mantle, therefore the steep incident angle at the shallow depth limits the resolution of the upper and middle crust heterogeneity. Differential traveltimes used here are sensitive only to the relative variation among the stations. To correct for the crustal heterogeneities, the crustal correction for each event station record was calculated based on the crust model for the station. We find that the main features of the inversion results are similar using several different crust models: SEAPS [Sun et al., 2004; Sun et al., 2008], CRUST2.0 [Bassin et al., 2000] and CUB2.0 [Shapiro and Ritzwoller, 2002].

[29] Huang et al. [2009] performed a joint inversion of local and teleseismic traveltimes using the data of the HIMNT, INDEPTH II and BHUTAN projects. They found a widespread middle crust low-velocity zone (at 30-50 km depth) beneath the North Himalaya (Tethyan Himalaya), which is not present in all of the crust models we tested for 

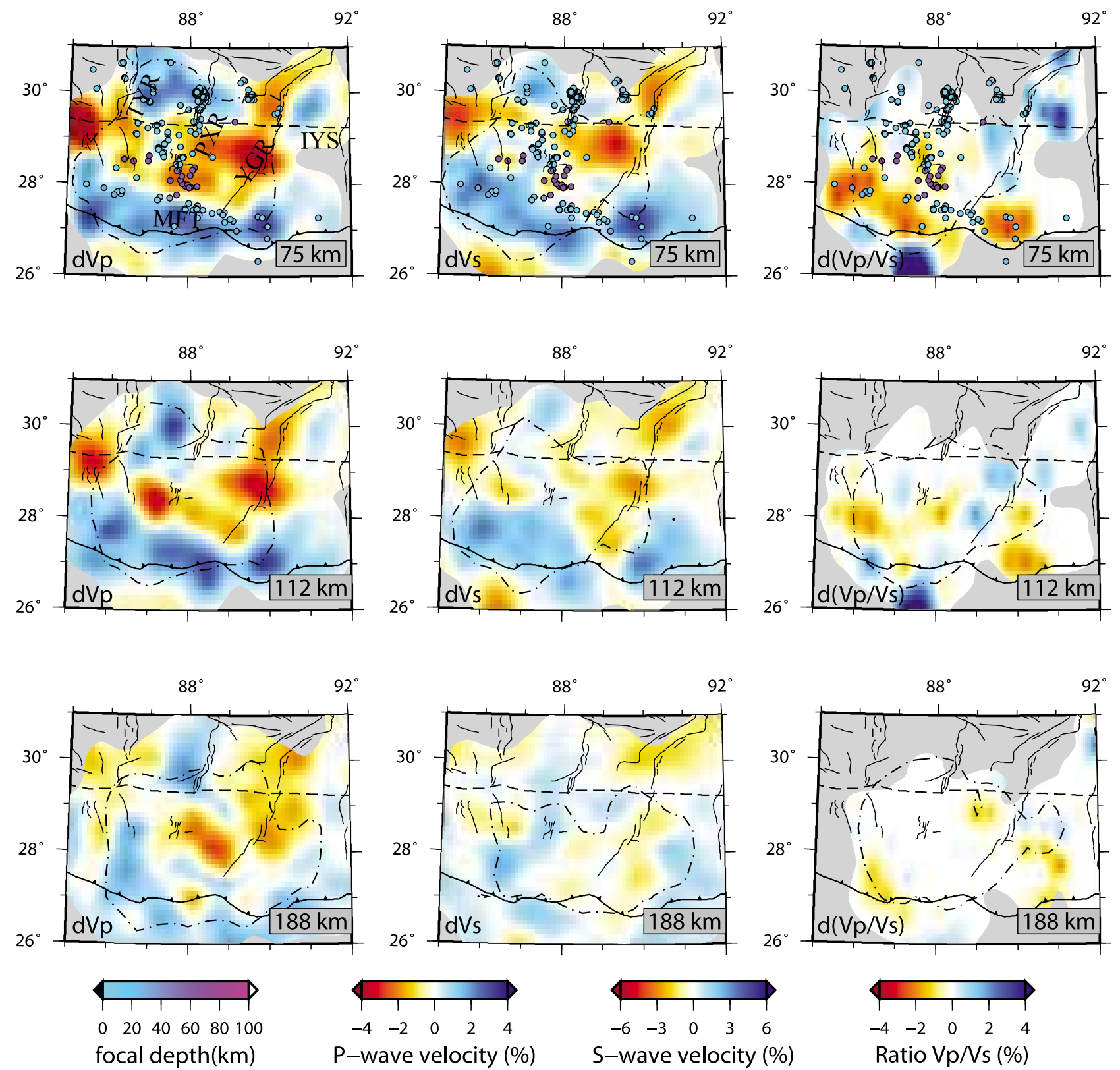

Figure 6a. Horizontal slices of the Vp, Vs, and Vp/Vs models of our inversion at three different depths of $75 \mathrm{~km}, 112 \mathrm{~km}$, and $188 \mathrm{~km}$. The Vp and Vs images are clipped along the boundary of $30 \%$ of the maximum kernel intensity for $P$ and $S$ traveltime sensitivity kernels. The $\mathrm{Vp} / \mathrm{Vs}$ images are similarly clipped based on the kernels of the selected $P$ traveltimes. The dot-dash line in each slice shows the $85 \%$ correlation coefficient contour in the checkerboard tests. In the top-left panel, several geological features are marked: IYS, Indus-Yalu suture; MFT, Main Frontal thrust; YGR, Yadong-Gulu rift; PXR, Pumqu-Xianza rift; TYR, Tangra Yum Co rift. The seismicity [Liang et al., 2008] is plotted as color-coded circles for different depths.

crustal correction. This midcrust low-velocity layer as well as a thicker crust could be partially responsible for the low $\mathrm{Vp}$ velocity anomaly at $75 \mathrm{~km}$ depth, although our relative travel times are not sensitive to horizontal structures.

\subsection{Rift and Nonrift Structures}

[30] Five 2-D profiles along the direction of the convergence between the Indian and Eurasian plates are presented in Figure $6 \mathrm{~b}$ to show the differences among these rifts and between rift and nonrift profiles. Three of them are along the rifts in southern Tibet and two (nonrift) profiles in between. Significant differences exist among these three rifts: a pronounced low $\mathrm{Vp}$ and $\mathrm{Vs}$ anomaly beneath the YGR, a reduced low Vp and Vs anomaly beneath the PXR, and little anomaly beneath the TYR. These differences reflect the lateral variation along the strike of Himalaya. Especially, the strong low $\mathrm{Vp}$ and Vs anomaly beneath the YGR, which we discuss in detail later.

[31] All the five profiles show clearly a low $\mathrm{Vp}$ anomaly (with a low $\mathrm{Vp} / \mathrm{Vs}$ ratio, except for the $\mathrm{DD}^{\prime}$ profile) at the 

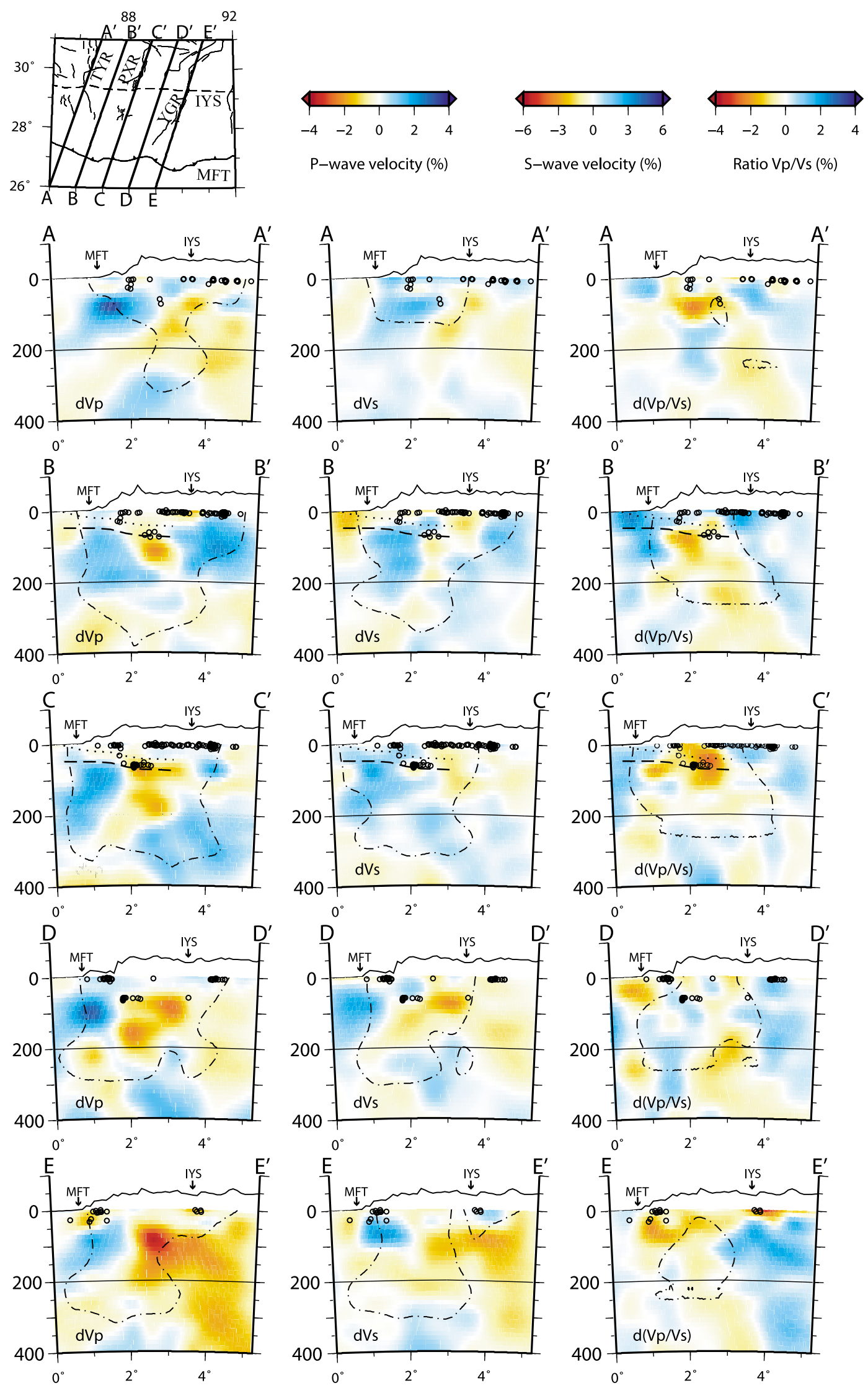

Figure 6b 

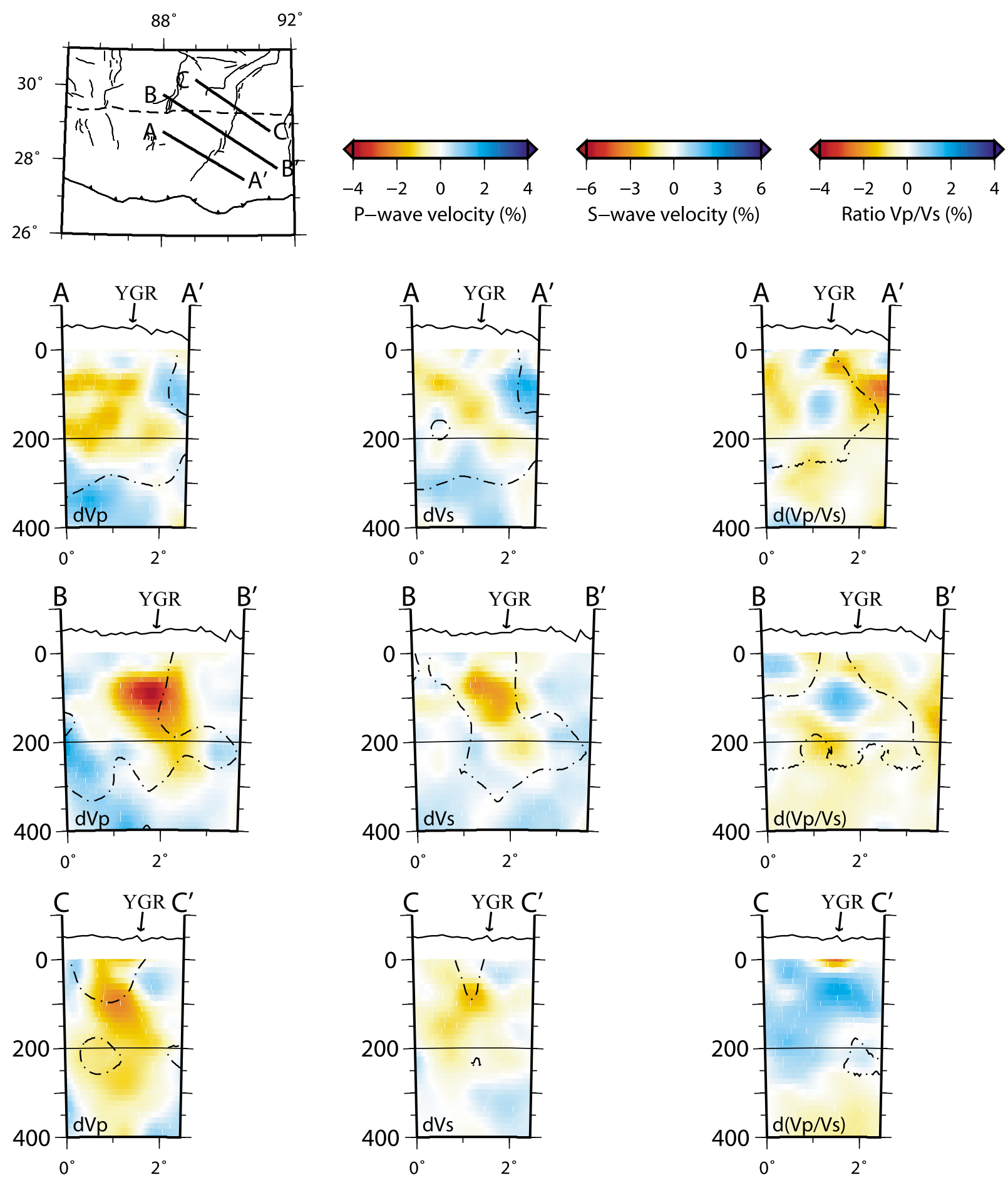

Figure 7. Vertical slices are perpendicular to the Yadong-Gulu rift from south to north, showing the low $\mathrm{Vp}$, Vs, and high $\mathrm{Vp} / \mathrm{Vs}$ ratio perturbations extending to at least $200 \mathrm{~km}$ depth.

Figure 6b. Vertical slices along the plate convergence direction. The Indian lower crust (Main Himalaya thrust (MHT)) and Moho [Schulte-Pelkum et al., 2005] are shown as a dotted line and a dashed line on BB' and CC', respectively. Geological structures are the same as the ones in horizontal slices. The dot-dash lines enclose the regions with correlation coefficient greater than $85 \%$. The topography is exaggerated by 10 times. The black circles show the seismicity within $70 \mathrm{~km}$ of the profiles and projected on the profiles. 

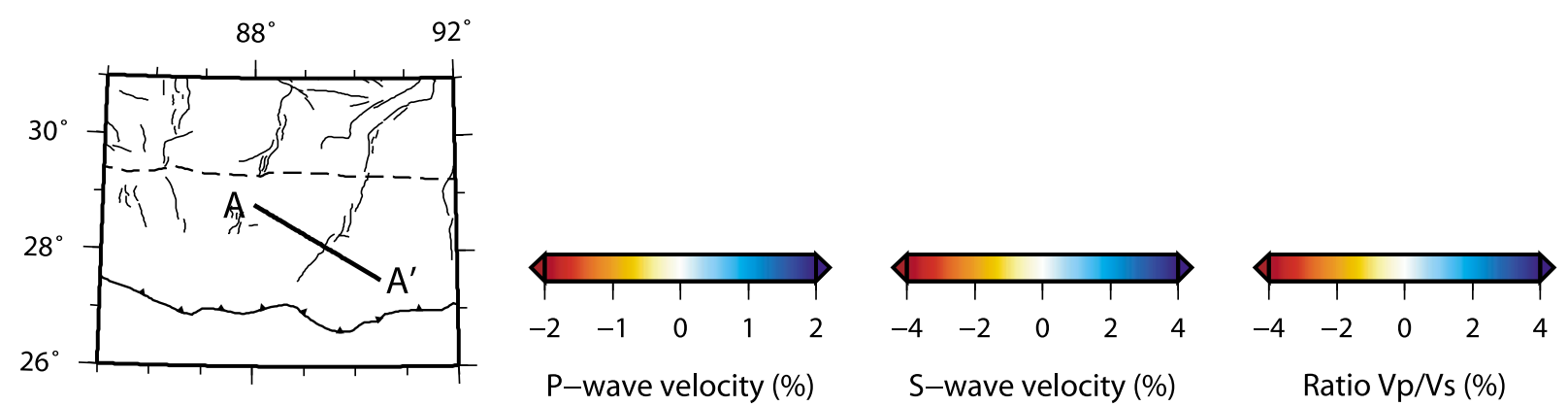

Input Model
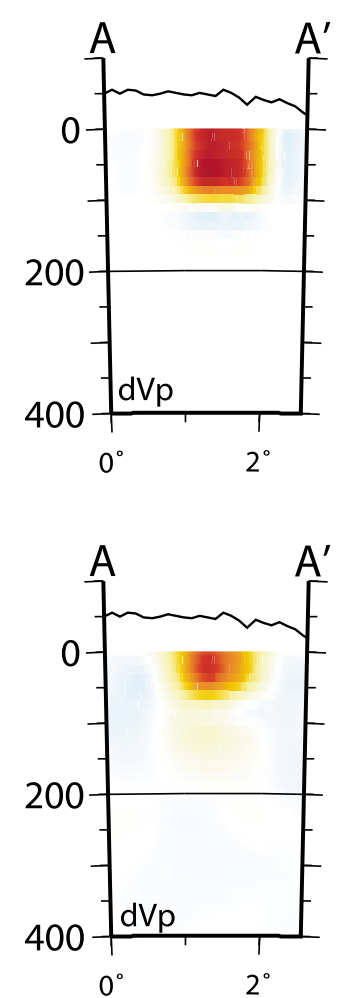

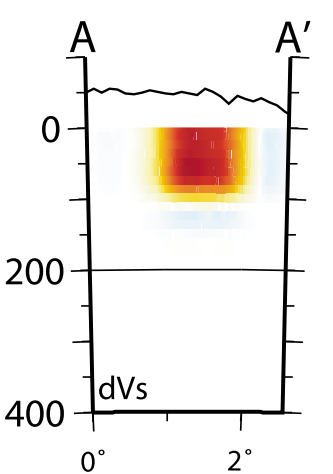

Inverted Model

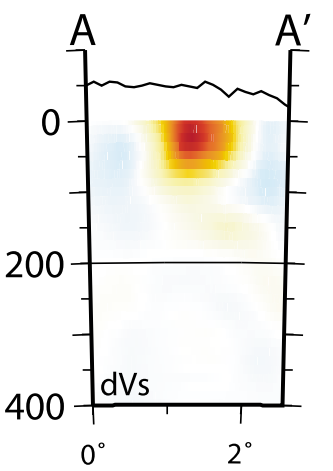

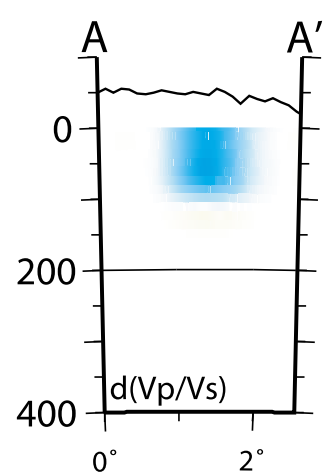

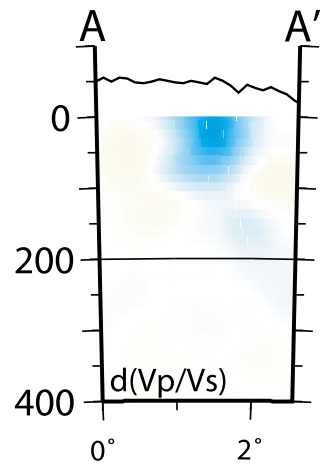

Figure 8. Vertical slices are perpendicular to the Yadong-Gulu rift for a block resolution test, showing the input low $\mathrm{Vp}$, Vs and high $\mathrm{Vp} / \mathrm{Vs}$ ratio perturbations in the crust are not smeared down to the upper mantle.

Moho depth $(75 \mathrm{~km})$ beneath the North Himalaya which is also the location of the hypocenters of the intermediate-depth earthquakes (Figure 6b) [Monsalve et al., 2006; Liang et al., 2008]. These earthquakes near the Moho have been suggested to be associated with the eclogitization of the subducting Indian lower crust [Jackson et al., 2004] and if this is true, a positive $\mathrm{Vp}$ anomaly should be observed [Monsalve et al., 2008]. This inconsistency is discussed later.

\subsection{The Yadong-Gulu Rift}

[32] The most notable rift among these roughly north-south trending rifts in southern Tibet is the YGR, which extends southward to $27.5^{\circ} \mathrm{N}$. Previous studies have shown that the central segment of the YGR initiated at about $8 \mathrm{Ma}$ ago and has accommodated $>20 \mathrm{~km}$ of east-west extension [Harrison et al., 1995] while recent analysis of U-Pb, $\mathrm{Ar} / \mathrm{Ar},(\mathrm{U}-\mathrm{Th}) / \mathrm{He}$ has suggested a younger age of $5 \mathrm{Ma}$ for the onset of these rifts [Maheo et al., 2007]. Both age estimates are different from the estimate of the Neogene ultrapotassic and adakitic magmatism ( $\sim 26$ to $13 \mathrm{Ma}$ ) in southern Tibet [Chung et al., 2005]. The significant age difference between the onset of the rifting and the Neogene magmatism implies that they were associated with different tectonic processes or at least different stages of the tectonic process.

[33] Figure 7 shows three profiles of the resulting Vp, Vs, and $\mathrm{Vp} / \mathrm{Vs}$ ratio across the rift from south to north. A strong low-velocity anomaly in both $\mathrm{Vp}$ and $\mathrm{Vs}$ is observed beneath the rift from Moho down to at least $200 \mathrm{~km}$ depth. A corresponding positive anomaly in $\mathrm{Vp} / \mathrm{Vs}$ ratio is centered at $100 \mathrm{~km}$ depth on profile $\mathrm{BB}^{\prime}$ of Figure 7, indicating a likely thermal origin for this feature because of a higher sensitivity of Vs to a temperature increase at these depths. The resolution test with a low Vp and Vs anomaly in the crust beneath the YGR shows that an input velocity anomaly in the crust is not smeared down significantly to the upper mantle in our inversion (Figure 8). Combined with the vertical resolution 
test (Figure 5), it is clear that the velocity anomalies in the mantle beneath the YGR are not due to up-down smearing of the crust structure.

[34] Together with the GPS measurements [Larson et al., 1999; Chen et al., 2004] and focal mechanisms of intermediate-depth earthquakes [Chen and Yang, 2004; de la Torre and Sheehan, 2005], these observations indicate that the rift is associated with processes in the mantle. Results from $P n$ tomography also showed the presence of a lowvelocity belt in the uppermost mantle beneath the YGR [Hearn et al., 2004; Liang and Song, 2006; Pei et al., 2007].

[35] A similar low-velocity anomaly in Vp and Vs was also observed at the Coma rift to the east of the YGR [Ren and Shen, 2008]. Beneath the low-velocity zone of the rift, there is a tabular, high-dipping angle, high-velocity, but low $\mathrm{Vp} / \mathrm{Vs}$ ratio anomaly, which indicates a highly melt-depleted mantle. Ren and Shen [2008] interpreted that high-velocity, low $\mathrm{Vp} / \mathrm{Vs}$ anomaly as an evidence supporting the delamination of the mantle lithosphere beneath southern Tibet, a process in which the mantle lithosphere peels away from crust and induces a rapid lithosphere thinning. Beneath the lowvelocity anomaly of the YGR, we cannot resolve any such anomaly and discriminate the mantle processes that may have caused or facilitated rifting. Nevertheless the observation of low-velocity anomalies beneath the YGR reconfirms that the north-south trending rifts in southern Tibet could be related to a coherent deformation of the crust and upper mantle.

\subsection{Eclogitization of the Indian Lower Crust}

[36] Le Pichon et al. [1992] pointed out that the volume of the present-day Indian and Eurasian crust cannot balance the total estimated amount of the crust that has entered into the collision zone and the eastern mass extrusion accounts for no more than one third of the deficit. One possible explanation for the missing crust is that a significant amount of the Indian lower crust has been transferred into the mantle by eclogitization, a process that transforms granulite to eclogite. Thermal-kinematic and petrological models suggest that eclogitization could take place at the P-T conditions in the lowermost crust of the Higher Himalaya [Henry et al., 1997]. Incorporating geophysical constraints with thermalkinematic and petrological modeling, Hetényi et al. [2007] found that the major density jump in the Indian lower crust occurs when it reaches $\sim 70 \mathrm{~km}$ depth beneath the Higher Himalaya. Receiver functions reveal a low-velocity contrast across the Moho north of the Higher Himalaya, reflecting a higher velocity in the lower crust, which could be an indication for the presence of partial eclogitization [SchultePelkum et al., 2005].

[37] Evidence for the transfer of eclogitized crust into the mantle has been more elusive. Observations of a high velocity beneath the Moho from a wide-angle reflection line situated between the Higher Himalaya and the IYS were interpreted as evidence for eclogite just beneath the seismic Moho [Spain and Hirn, 1997]. Using $P$ and $S$ wave traveltimes from local earthquakes recorded by the HIMNT network, Monsalve et al. [2008] found a significantly high $\mathrm{Vp}$ velocity (over $8.4 \mathrm{~km} / \mathrm{s}$ ) in the uppermost mantle north of $27.5^{\circ} \mathrm{N}$. Together with a relatively low $\mathrm{Vp} / \mathrm{Vs}$ ratio compared to that of an average uppermost mantle, the high $\mathrm{Vp}$ velocity was interpreted as evidence for the presence of eclogite under the Moho [Monsalve et al., 2008]. In contrast to this high Vp in the uppermost mantle, our results show a localized, low Vp, normal-to-high $\mathrm{Vs}$, and low $\mathrm{Vp} / \mathrm{Vs}$ anomaly that extends at the general vicinity of the intermediate-depth earthquakes beneath the North Himalaya (Figures 6a and 6b). The resolution (Figure 5) and null-space shuttle (Figure 9) tests show that this anomaly is a robust feature required by the traveltime data. One possible explanation for the discrepancy between Monsalve et al. [2008] and this study is that the model of Monsalve et al. [2008] reflects a 2-D structure averaged in the direction perpendicular to the plate convergence, while the 3-D teleseismic tomography using relative traveltimes is sensitive to lateral velocity heterogeneities but insensitive to a constant velocity change at the same depth.

[38] A low temperature, a high Magnesium number $(\mathrm{Mg}$ number, $\mathrm{Mg} /(\mathrm{Mg}+\mathrm{Fe}))$, or a low garnet/olivine ratio could cause a low $\mathrm{Vp} / \mathrm{Vs}$ ratio in the uppermost mantle [Boyd et al., 2004]. Orthopyroxene-rich zones within the peridotitic lithospheric mantle also show as a low $P$ wave velocity, with only a small decrease in the $S$ wave velocity and a low $\mathrm{Vp} / \mathrm{Vs}$ ratio [Miller and Lee, 2008]. But none of these mechanisms could explain both the low Vp and high Vs of this anomalous feature around the intermediate-depth earthquakes (Figures 6a, 6b, and 9).

[39] Jackson et al. [2004] attributed the intermediate-depth earthquakes in southern Tibet to the transformation process of the lower crust from granulite to eclogite. Studies from two high-pressure complexes in Norway [Lund et al., 2004] found that deeply subducted dry rocks in the lowermost continental crust may resist metamorphic re-equilibration for geologically significant periods of time. Their observations indicate that the brittle seismogenic state of some lower crustal rocks is largely controlled by their very low volatile contents, which keep the rocks metamorphically metastable despite at mantle conditions of T $=600-800^{\circ} \mathrm{C}$ and $P=1.5-$ $2.0 \mathrm{GPa}$. Dry rocks under high stress may fail by hightemperature and high-pressure faulting if crystal plasticity is unable to accommodate the imposed strain [Shelton et al., 1981]. The occurrence of intermediate-depth earthquakes in the Himalayas could represent the presence of metastable dry granulite within the lower continental crust and its ongoing transformation to eclogite.

[40] Eclogite, which is composed predominantly of omphacitic pyroxene and $\mathrm{Ca}-\mathrm{Fe}-\mathrm{Mg}$-rich garnet, generally has higher $\mathrm{Vp}$ and even higher $\mathrm{Vs}$ in percentage compared to those of the peridotitic uppermost mantle [Ji et al., 2002]. However, in a rock with coexisting high- and low-pressure phases, such as the granulite-eclogite or garnet granuliteeclogite system, the effective bulk modulus could be significantly lowered if the pressure of seismic waves drives the volume-reducing phase transformation [Anderson, 1989]. Using experimental data, $L i$ and Weidner [2008] demonstrated the softening of the bulk modulus within the twophase loop of olivine-ringwoodite on time scales of 10 to $1000 \mathrm{~s}$, and suggested that seismic waves with periods between 1 and $1000 \mathrm{~s}$ could at least partially drive the phase transition and result in partially relaxed $P$ velocities.

[41] The effects of seismic waves on the effective bulk modulus of a rock with coexisting (garnet) granulite and eclogite are likely controlled by diffusion between the minerals in metastable (garnet) granulite and eclogite, though the exact effects are unknown. Nevertheless, we may obtain a rough estimate of the characteristic time of the transformation 

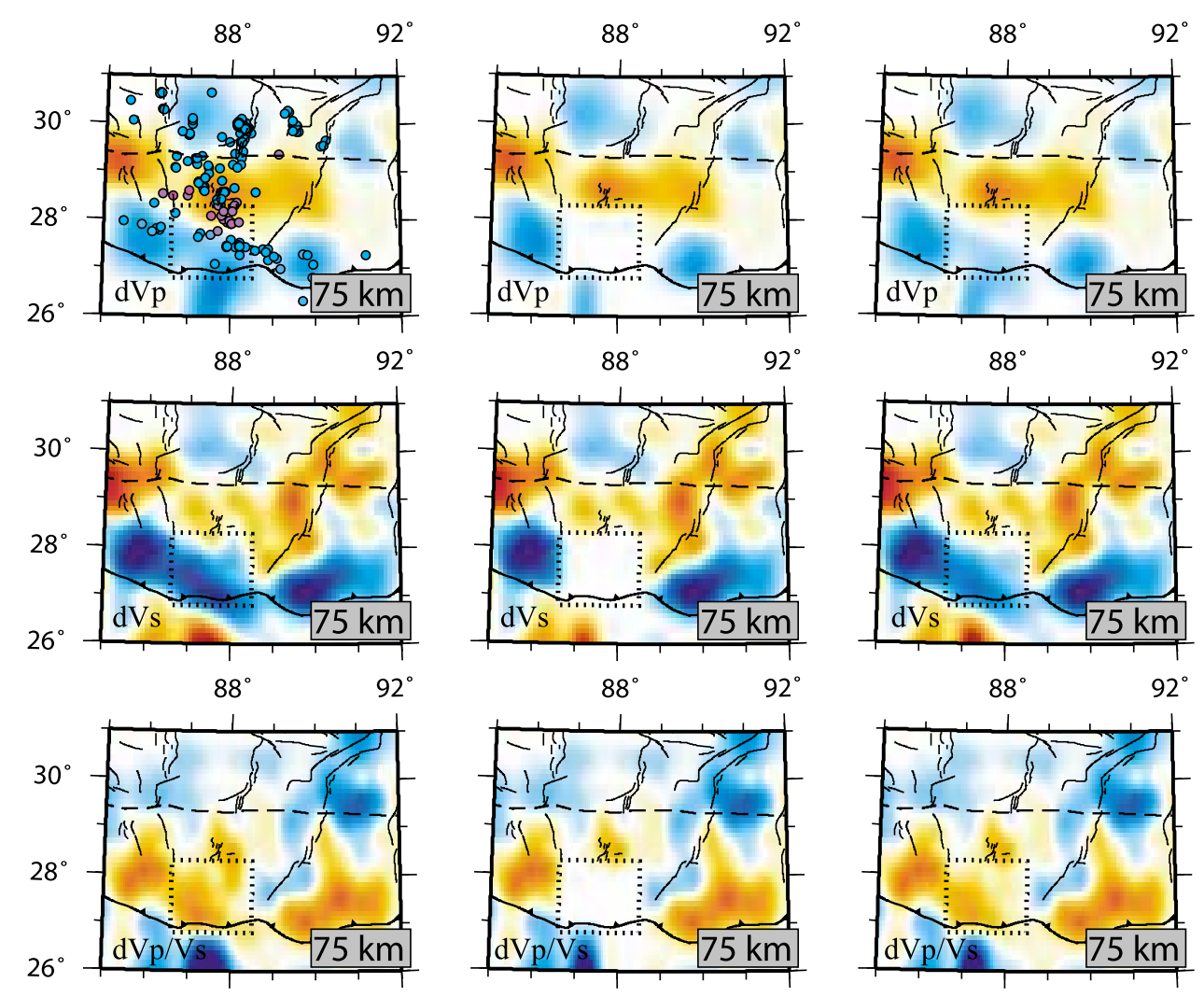

a. Original inverted model

b. Filtered model

c. Conservative model
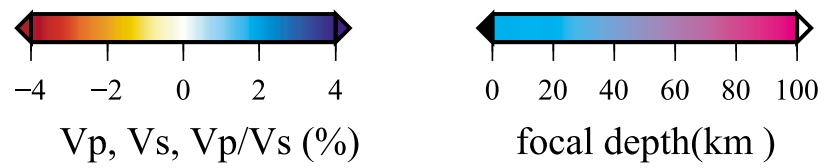

Figure 9. (top) Vp, (middle) Vs, and (bottom) Vp/Vs ratio models for null-space shuttle test. Our preferred models (left), filtered models (middle), and (right) the conservatively filtered models after the null-space shuttle test. In the filtered models, the anomalous $\mathrm{Vp} / \mathrm{Vs}$ feature outlined by the dotted line is removed. Color-coded seismicity [Liang et al., 2008] representing earthquake depths shows the intermediatedepth earthquakes (upper left) are in the vicinity of the low $\mathrm{Vp} / \mathrm{Vs}$ ratio anomaly.

using the iron-magnesium exchange rate for garnet. Following $L i$ and Weidner [2008] the characteristic transformation time $\left(\tau_{1}\right.$ in the work of Li and Weidner [2008]) is $\sim 10^{-2} \mathrm{~s}$ if we assume a grain size of $1 \mathrm{~mm}$, a pressure perturbation caused by seismic waves of $10^{-7} \mathrm{GPa}$, and a width of the pressure of the transformation of $\sim 1 \mathrm{GPa}$, and a diffusion coefficient of $10^{-19} \mathrm{~m}^{2} \mathrm{~s}^{-1}$ at $800^{\circ} \mathrm{C}$ [Freer and Edwards, 1999]. A larger grain size, smaller width of transformation pressure, or lower temperature increases $\tau_{1}$, while the opposite reduces $\tau_{1}$. Although $\tau_{1}$ is quite variable and has large uncertainties, this exercise shows that the softening of the bulk modulus in the (garnet) granulite-eclogite system and thus a reduction in $P$ wave velocity is possible within the frequency band of teleseismic $P$ waves used in this study $(0.1-2 \mathrm{~Hz})$. On the other hand, high-frequency $P$ waves used in local earthquake tomography [Monsalve et al., 2008] may have a significantly less softening of the bulk modulus. Using local and teleseismic $P$ waves, Huang et al. [2009] found a high Vp immediately beneath the Moho $(76-83 \mathrm{~km})$ in the vicinity of the intermediate-depth earthquakes $\left(28^{\circ} \mathrm{N}, 88^{\circ} \mathrm{E}\right)$, but a low
Vp anomaly at depths of 99 and $119 \mathrm{~km}$. The crust and uppermost mantle are presumably constrained primarily by local, high-frequency $P$ and $P n$ waves, while the deeper structure is constrained by relatively lower frequency, teleseismic $P$ waves in Huang et al. [2009]. So the frequencydependent wave speeds of the granunite-eclogite transformation also offer a possible explanation for the discrepancy between Huang et al. [2009] and this study. The volumereducing transformation has little effect on the shear modulus and shear velocity. The combined effects of the softening of the bulk modulus in a (garnet) granulite-eclogite system and a relative low temperature may account for the simultaneous occurrence of low Vp, high Vs and low Vp/Vs anomalies.

[42] In this scenario, the intermediate-depth earthquakes and the underlying low $\mathrm{Vp} / \mathrm{Vs}$ anomaly are both indications of the lower crustal material being transferred into the mantle and an ongoing granulite-eclogite transformation. The mechanisms of the transfer can be passive by the coupling of part of the lower crust to the subducting mantle lithosphere or dynamic because of the negative buoyancy of an eclogitized 

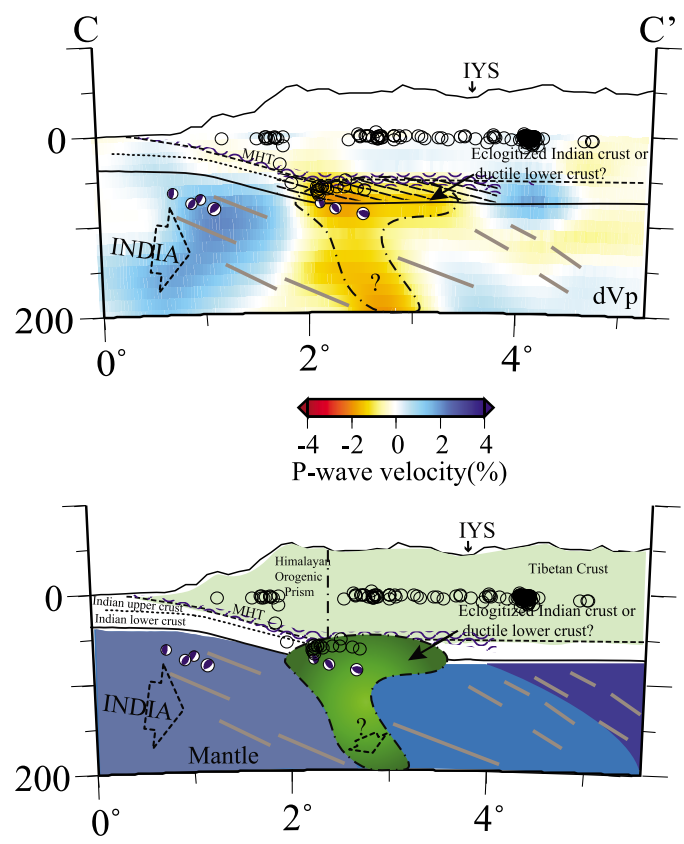

Figure 10. Geodynamic interpretations superimposed on the $\mathrm{Vp}$ perturbation images along the $\mathrm{CC}^{\prime}$ profiles of Figure 6. The Indian lithosphere underthrusts to the Higher Himalaya and the Indian crust feeds into the Tibetan crust. Sinking of the eclogitized lower crust because of negative buoyancy may be partially responsible for the separation of the Indian mantle lithosphere from the seismic Moho farther north. Our tomographic model supports the notion that the Indian lithosphere subducts in a progressive, piecewise and subparallel fashion shown as different blue colors as different episodes of subduction. The model cartoon is modified from Nabelek et al. [2009]. The eclogitized lower crust is shown in green. Moho is shown as a black line. Focal mechanisms mark mantle earthquakes [Chen and Yang, 2004]. The MHT, which becomes a broader midcrustal LVZ (blue wavy pattern) beneath the North Himalaya, accommodates the simple shear of the plate motions and acts as a conduit for the transfer of the Indian upper crust into the Himalayan orogenic prism, as the middle crust low velocity zone imaged by Huang et al. [2009]. The prominent lineations of the upper mantle fabric are shown in gray lines.

crust depending on the extent of eclogitization and the effective bulk viscosity of the eclogitized crust.

\subsection{The Indian Mantle Lithosphere}

[43] Whether the Indian mantle lithosphere underthrusts subhorizontally and continuously to the Bangong-Nujiang suture or subducts at an angle [Tilmann et al., 2003; Li et al., 2008 ] is an important question to understand the evolution of the Tibetan Plateau. The presence of $200 \mathrm{~km}$ deep lowvelocity anomalies beneath the north-south-trending rifts in south Tibet imaged in this study and to the east [Ren and Shen, 2008] suggests that an underthrusted Indian mantle lithosphere, if present before rifting, would have been broken into pieces by the rifting processes started in the late stage of the plateau building and the surface rifts correspond to and are possibly controlled by the boundaries of the broken mantle lithosphere [Yin, 2000]. Local asthenospheric upwelling could drive the rifting process at the surface and is observed as the negative velocity anomalies in both $\mathrm{Vp}$ and $\mathrm{Vs}$ shown in Figure 7. Individual pieces of the Indian mantle lithosphere could have undergone separate evolution since, driven by local forces acting on the individual pieces and resulting in differences in the geometry of the Indian mantle lithosphere from west to east Tibet. Alternatively rifting involves only the overriding Eurasian plate. In this scenario, the northern extend of subhorizontal underthrusting of the Indian lithospheric mantle is limited to the North Himalaya in the study area and the Indian lithospheric mantle that entered the collision zone earlier has either been peeled off from the Moho of the Tibetan crust or has subducted into deeper mantle [ $\mathrm{Li}$ et al., 2008].

[44] If the low $\mathrm{Vp} / \mathrm{Vs}$ region indeed reflects eclogitization of crustal material as we suggest, it is inconsistent with a continuous underthrusting of the Indian mantle lithosphere right beneath the seismic Moho, because the low Vp/Vs region extends below the seismic Moho. It requires the separation of the Indian mantle lithosphere from the lower crust beneath the Higher Himalaya. Together with the compressional stress from the collision, eclogitization and the associated negative buoyancy force offer a plausible mechanism that causes the sinking and subduction of the Indian mantle lithosphere beneath the Higher Himalaya. Since our observation is a snapshot of a limited extent, it does not exclude the possibility of the existence of an underthrusted Indian mantle lithosphere right beneath the seismic Moho in north Tibet.

[45] Also inconsistent with a simple, continuous underthrusted Indian mantle lithosphere right beneath the seismic Moho are the north dipping lineations with about a $20^{\circ}$ angle in the upper mantle found from seismic reflection data [Alsdorf et al., 1996], receiver function images along the main profile of the Hi-CLIMB experiment [Nabelek et al., 2009] and local and teleseismic joint tomography [Huang et al., 2009]. These mantle fabrics cannot be explained with simple underthrusting. Furthermore they suggest that in the past 20 to 25 million years, the mantle has not been subducting along a single well-established interface but rather along distributed, evolving subparallel structures, which imply a degree of decoupling between the crust and the mantle [Nabelek et al., 2009]. Taking these observations into consideration, our preferred scenario is that the Indian mantle lithosphere has been broken laterally in the direction perpendicular to the convergence and has subducted in a progressive, piecewise and subparallel fashion with the current one beneath the Higher Himalaya (Figure 10).

\section{Conclusion}

[46] Our finite-frequency body wave tomography models show that there is a low $\mathrm{Vp} / \mathrm{Vs}$ anomaly below a cluster of intermediate-depth earthquakes and the corner of the "rampand-flat" Moho geometry. This low $\mathrm{Vp} / \mathrm{Vs}$ anomaly is unusual as it is associated with a low Vp but normal to high Vs velocities. This anomaly cannot be explained by a simple thermal or compositional (e.g., volatiles) heterogeneity. We attribute it to pressure softening because of the coexistence of eclogite and (garnet) granulite in a partially transformed, former Indian lower crust. If true, the partial removal and 
sinking of an eclogitized lower crust provides a possible explanation for the deficit in the mass balance of the shortened and thickened crust of the Himalayas and Tibetan Plateau.

[47] The low Vp and Vs anomalies extending to more than $200 \mathrm{~km}$ depth beneath the YGR and possibly TYR are evidence that deformation associated with the rifts cuts through the whole crust and mantle lithosphere. This supports the previous observation by Ren and Shen [2008] that the northsouth trending rifts in southern Tibet are lithospheric-scale features. Significant variations in velocity structures do exist between the profiles along the rifts and those between the rifts.

[48] There is a high Vp and Vs anomaly that extends from the Moho to about $200 \mathrm{~km}$ depth along the Higher Himalaya. This high-velocity anomaly is attributed to the Indian mantle lithosphere. Together with evidence for north dipping lineations in the mantle [Nabelek et al., 2009; Huang et al., 2009], our observations suggest that the Indian mantle lithosphere has been broken laterally in the direction perpendicular to the convergence beneath the North Himalaya and subducted in a progressive, piecewise and subparallel fashion with the current one beneath the Higher Himalaya (Figure 10).

[49] Acknowledgments. We thank all the members of the Hi-CLIMB team, who collected a large part of the data used in this study. Constructive comments by two anonymous reviewers helped improve the manuscript. Discussions with Eric Sandvol helped the interpretation of our results. We also acknowledge the IRIS DMC and the INDEPTH, HIMNT and BHUTAN experiments for making seismic data available. The Generic Mapping Tools (GMT) is used in producing all the figures. Seismic Analysis Code (SAC) is used for data processing. The Peking University component of the fieldwork in the Hi-CLIMB project is supported by NSFC grants for international collaboration (40520120222, 40821062). Xiaofeng Liang is supported by the China Scholarship Council during his visit at the University of Rhode Island. Yang Shen is supported by a U.S. NSF grant (0738779).

\section{References}

Alsdorf, D., L. Brown, and D. Nelson (1996), Possible upper mantle reflection fabric on seismic profiles from the Tethyan Himalaya: Identification and tectonic interpretation, J. Geophys. Res., 101, 25,305-25,320, doi:10.1029/96JB02120.

Anderson, D. L. (1989), Theory of the Earth, Blackwell Sci., Boston, Mass. Argand, E. (1924), La tectonique de l'Asie, Rep. Sess. 13/1, pp. 170-168, Int. Geol. Congr., Paris.

Armijo, R., P. Tapponnier, J. P. Mercier, and T. Han (1986), Quaternary extension in southern Tibet, J. Geophys. Res., 91, 13,803-13,872, doi:10.1029/JB091iB14p13803.

Armijo, R., P. Tapponnier, and T. Han (1989), Late Cenozoic right-lateral strike-slip faulting across southern Tibet, J. Geophys. Res., 94, $2787-$ 2838, doi:10.1029/JB094iB03p02787.

Bassin, C., G. Laske, and G. Masters (2000), The current limits of resolution for surface wave tomography in North America, Eos Trans. $A G U$, $81,897$.

Boyd, O. S., C. H. Jones, and A. F. Sheehan (2004), Foundering lithosphere imaged beneath the southern Sierra Nevada, California, USA, Science, 305, 660-662, doi:10.1126/science.1099181.

Brown, L. D., W. Zhao, K. D. Nelson, M. Hauck, D. Alsdorf, A. Ross, M. Cogan, M. Clark, X. Liu, and J. Che (1996), Bright spots, structure and magmatism in southern Tibet from INDEPTH seismic reflection profiling, Science, 274, 1688-1690, doi:10.1126/science.274.5293.1688.

Chen, L., J. R. Booker, A. G. Jones, N. Wu, M. J. Unsworth, W. Wei, and H. Tan (1996), Electrically conductive crust in southern Tibet from INDEPTH magnetotelluric surveying, Science, 274, 1694-1696, doi:10.1126/science.274.5293.1694.

Chen, Q., J. T. Freymueller, Z. Yang, C. Xu, W. Jiang, Q. Wang, and J. Liu (2004), Spatially variable extension in southern Tibet based on GPS measurements, J. Geophys. Res., 109, B09401, doi:10.1029/2002JB002350. Chen, W., and P. Molnar (1983), Focal depths of intracontinental and intraplate earthquakes and their implications for the thermal and mechanical properties of the lithosphere, J. Geophys. Res., 88, 4183-4214 doi:10.1029/JB088iB05p04183.

Chen, W., J. Nabelek, T. Fitch, and P. Molnar (1981), An intermediate depth earthquake beneath Tibet: Source characteristics of the event of September 14, 1976, J. Geophys. Res., 86, 2863-2876, doi:10.1029/ JB086iB04p02863.

Chen, W. P., and Z. Yang (2004), Earthquakes beneath the Himalayas and Tibet: Evidence for strong lithospheric mantle, Science, 304, 1949-1952, doi:10.1126/science. 1097324.

Chiao, L. Y., and B. Y. Kuo (2001), Multiscale seismic tomography, Geophys. J. Int., 145, 517-527, doi:10.1046/j.0956-540x.2001.01403.x. Chung, S. L., M. F. Chu, Y. Zhang, Y. Xie, C. H. Lo, T. Y. Lee, C. Y. Lan, X. Li, Q. Zhang, and Y. Wang (2005), Tibetan tectonic evolution inferred from spatial and temporal variations in post-collisional magmatism, Earth Sci. Rev., 68, 173-196, doi:10.1016/j.earscirev.2004.05.001.

Conder, J. A., and D. A. Wiens (2006), Seismic structure beneath the Tonga arc and Lau back-arc basin determined from joint $\mathrm{Vp}, \mathrm{Vp} / \mathrm{Vs}$ tomography, Geochem. Geophys. Geosyst., 7, Q03018, doi:10.1029/ 2005 GC001113.

Dahlen, F. A., S.-H. Hung, and G. Nolet (2000), Fréchet kernels for finitefrequency traveltimes-I. Theory, Geophys. J. Int., 141, 157-174, doi:10.1046/j.1365-246X.2000.00070.x.

Deal, M. M., and G. Nolet (1996), Nullspace shuttles, Geophys. J. Int., 124, 372-380, doi:10.1111/j.1365-246X.1996.tb07027.x.

de la Torre, T., and A. Sheehan (2005), Broadband seismic noise analysis of the Himalayan Nepal Tibet seismic experiment, Bull. Seismol. Soc. Am., 95, 1202-1208, doi:10.1785/0120040098.

Eberhart-Phillips, D. (1990), Three-dimensional $P$ and $S$ velocity structure in the Coalinga region, California, J. Geophys. Res., 95, 15,343-15,363, doi:10.1029/JB095iB10p15343.

Freer, R., and A. Edwards (1999), An experimental study of $\mathrm{Ca}-(\mathrm{Fe}, \mathrm{Mg})$ interdiffusion in silicate garnets, Contrib. Mineral. Petrol., 134(4), 370 379, doi:10.1007/s004100050491.

Fu, Y. Y. V., Y. J. Chen, A. B. Li, S. Y. Zhou, X. F. Liang, G. Y. Ye, G. Jin, M. M. Jiang, and J. Y. Ning (2008), Indian mantle corner flow at southern Tibet revealed by shear wave splitting measurements, Geophys. Res. Lett., 35, L02308, doi:10.1029/2007GL031753.

Harrison, T. M., P. Copeland, W. S. F. Kidd, and O. M. Lovera (1995), Activation of the Nyainqentanghla shear zone: Implications for uplift of the southern Tibetan Plateau, Tectonics, 14, 658-676, doi:10.1029/ 95TC00608.

Hearn, T. M., S. Wang, J. F. Ni, Z. Xu, Y. Yu, and X. Zhang (2004), Uppermost mantle velocities beneath China and surrounding regions, J. Geophys. Res., 109, B11301, doi:10.1029/2003JB002874.

Henry, P., X. LePichon, and B. Goffe (1997), Kinematic, thermal and petrological model of the Himalayas: Constraints related to metamorphism within the underthrust Indian crust and topographic elevation, Tectonophysics, 273(1-2), 31-56, doi:10.1016/S0040-1951(96)00287-9.

Hetényi, G., R. Cattin, F. Brunet, L. Bollinger, J. Vergne, J. Nabelek, and M. Diament (2007), Density distribution of the India plate beneath the Tibetan Plateau: Geophysical and petrological constraints on the kinetics of lower-crustal eclogitization, Earth Planet. Sci. Lett., 264(1-2), 226244, doi:10.1016/j.eps1.2007.09.036.

Hirn, A., et al. (1995), Seismic anisotropy as an indicator of mantle flow beneath Himalayas and Tibet, Nature, 375, 571-574, doi:10.1038/ $375571 \mathrm{a} 0$.

Hoke, L., S. Lamb, D. R. Hilton, and R. J. Poreda (2000), Southern limit of mantle-derived geothermal helium emissions in Tibet: Implications for lithospheric structure, Earth Planet. Sci. Lett., 180(3-4), 297-308, doi:10.1016/S0012-821X(00)00174-6.

Huang, G.-C., F. T. Wu, S. W. Roecker, and A. F. Sheehan (2009), Lithospheric structure of the central Himalaya from 3-D tomographic imaging, Tectonophysics, 475, 524-543, doi:10.1016/j.tecto.2009.06. 023 .

Hung, S.-H., Y. Shen, and L.-Y. Chiao (2004), Imaging seismic velocity structure beneath the Iceland hot spot: A finite frequency approach, J. Geophys. Res., 109, B08305, doi:10.1029/2003JB002889.

Jackson, J. (2002), Strength of the continental Lithosphere: Time to abandon the jelly sandwich?, GSA Today, 12, 4-10, doi:10.1130/1052-5173 (2002)012<0004:SOTCLT $>2.0$. CO;2.

Jackson, J. A., H. Austrheim, D. McKenzie, and K. Priestley (2004), Metastability, mechanical strength, and the support of mountain belts, Geology, 32, 625-628, doi:10.1130/G20397.1.

Ji, S. C., Q. Wang, and B. Xia (2002), Handbook of Seismic Properties of Minerals, Rocks and Ores, 630 pp., Polytechnic, Montreal, Que., Canada. Jin, G., Y. J. Chen, E. Sandvol, S. Zhou, Y. Tang, X. Liang, G. Ye, D. Wilson, and J. Nabelek (2006), Receiver function images of the crust and upper mantle structure of southern Tibet, Eos Trans. AGU, 87(52), Fall Meet. Suppl., Abstract T53F-04. 
Jin, Y., M. K. McNutt, and Y. Zhu (1996), Mapping the descent of Indian and Eurasian plates beneath the Tibetan Plateau from gravity anomalies, J. Geophys. Res., 101, 11,275-11,290, doi:10.1029/96JB00531.

Kennett, B. L. N., S. Widiyantoro, and R. D. van der Hilst (1998), Joint seismic tomography for bulk sound and shear wave speed in the Earth's mantle, J. Geophys. Res., 103, 12,469-12,493, doi:10.1029/98JB00150.

Kind, R., et al. (2002), Seismic images of crust and upper mantle beneath Tibet: Evidence for Eurasian plate subduction, Science, 298, 1219-1221, doi:10.1126/science. 1078115 .

Kosarev, G., R. Kind, S. V. Sobolev, X. Yuan, W. Hanka, and S. Oreshin (1999), Seismic evidence for a detached India lithospheric mantle beneath Tibet, Science, 283, 1306-1309, doi:10.1126/science.283.5406. 1306.

Kumar, P., X. Yuan, R. Kind, and J. Ni (2006), Imaging the colliding Indian and Asian lithospheric plates beneath Tibet, J. Geophys. Res., 111, B06308, doi:10.1029/2005JB003930.

Larson, K. M., R. Burgmann, R. Bilham, and J. T. Freymueller (1999), Kinematics of the India-Eurasia collision zone from GPS measurements, J. Geophys. Res., 104, 1077-1093, doi:10.1029/1998JB900043.

Le Pichon, X., M. Fournier, and L. Jolivet (1992), Kinematics, topography, shortening, and extrusion in the India-Eurasia collision, Tectonics, 11 , 1085-1098, doi:10.1029/92TC01566.

Li, C., R. D. v. d. Hilst, A. S. Meltzer, and E. R. Engdahl (2008), Subduction of the Indian lithosphere beneath the Tibetan Plateau and Burma Earth Planet. Sci. Lett., 274(1-2), 157-168, doi:10.1016/j.eps1.2008 07.016.

Li, L., and D. J. Weidner (2008), Effect of phase transitions on compressional-wave velocities in the Earth's mantle, Nature, 454, 984-986, doi:10.1038/nature07230.

Liang, C., and X. Song (2006), A low velocity belt beneath northern and eastern Tibetan Plateau from Pn tomography, Geophys. Res. Lett., 33 L22306, doi:10.1029/2006GL027926.

Liang, X., S. Zhou, Y. J. Chen, G. Jin, L. Xiao, P. Liu, Y. Fu, Y. Tang, X. Lou, and J. Ning (2008), Earthquake distribution in southern Tibet and its tectonic implications, J. Geophys. Res., 113, B12409, doi:10.1029/2007JB005101

Liu, L., J. F. Zhang, H. W. Green, Z. M. Jin, and K. N. Bozhilov (2007) Evidence of former stishovite in metamorphosed sediments, implying subduction to $>350 \mathrm{~km}$, Earth Planet. Sci. Lett., 263(3-4), 180-191.

Lund, M. G., H. Austrheim, and M. Erambert (2004), Earthquakes in the deep continental crust-insights from studies on exhumed high-pressure rocks, Geophys. J. Int., 158, 569-576, doi:10.1111/j.1365-246X.2004. 02368.x.

Maheo, G., P. H. Leloup, F. Valli, R. Lacassin, N. Arnaud, J. L. Paquette, A. Fernandez, L. Haibing, K. A. Farley, and P. Tapponnier (2007), Post $4 \mathrm{Ma}$ initiation of normal faulting in southern Tibet. Constraints from the Kung Co half graben, Earth Planet. Sci. Lett., 256(1-2), 233-243, doi:10.1016/j.epsl.2007.01.029.

Masek, J. G., B. L. Isacks, E. J. Fielding, and J. Browaeys (1994), Rift flank uplift in Tibet: Evidence for a viscous lower crust, Tectonics, 13, 659-667, doi:10.1029/94TC00452.

McCaffrey, R., and J. Nabelek (1998), Role of oblique convergence in the active deformation of the Himalayas and southern Tibet plateau, Geology, 26, 691-694, doi:10.1130/0091-7613(1998)026<0691: ROOCIT>2.3.CO;2.

Miller, M. S., and C.-T. A. Lee (2008), Possible chemical modification of oceanic lithosphere by hotspot magmatism: Seismic evidence from the junction of Ninetyeast Ridge and the Sumatra-Andaman arc, Earth Planet. Sci. Lett., 265(3-4), 386-395, doi:10.1016/j.eps1.2007.10.039.

Molnar, P., and P. Tapponnier (1978), Active tectonics of Tibet, J. Geophys. Res., 83, 5361-5375, doi:10.1029/JB083iB11p05361.

Monsalve, G., A. Sheehan, V. Schulte-Pelkum, S. Rajaure, M. R. Pandey, and F. Wu (2006), Seismicity and one-dimensional velocity structure of the Himalayan collision zone: Earthquakes in the crust and upper mantle, J. Geophys. Res., 111, B10301, doi:10.1029/2005JB004062.

Monsalve, G., A. Sheehan, C. Rowe, and S. Rajaure (2008), Seismic structure of the crust and the upper mantle beneath the Himalayas: Evidence for eclogitization of lower crustal rocks in the Indian Plate, J. Geophys Res., 113, B08315, doi:10.1029/2007JB005424.

Muñoz, G., and V. Rath (2006), Beyond smooth inversion: The use of nullspace projection for the exploration of non-uniqueness in MT, Geophys. J. Int., 164, 301-311, doi:10.1111/j.1365-246X.2005.02825.x.

Nabelek, J., J. Vergne, and G. Hetenyi (2005), A synoptic view of the Himalayan Collision Zone and southern Tibet, Eos Trans. AGU, 86(52), Fall Meet., Suppl., Abstract T52A-02.

Nabelek, J., G. Hetenyi, J. Vergne, S. Sapkota, B. Kafle, M. Jiang, H. Su, J. Chen, B-S. Huang, and the Hi-CLIMB Team (2009), Underplating in the Himalaya-Tibet collision zone revealed by the Hi-CLIMB experiment, Science, 325, 1371-1374, doi:10.1126/science.1167719.
Nakajima, J., T. Matsuzawa, A. Hasegawa, and D. P. Zhao (2001), Threedimensional structure of $V_{p}, V_{s}$, and $V_{p} / V_{s}$ beneath northeastern Japan: Implications for arc magmatism and fluids, J. Geophys. Res., 106 , 21,843-21,857, doi:10.1029/2000JB000008.

Nakamura, M., Y. Yoshida, D. P. Zhao, H. Katao, and S. Nishimura (2003), Three-dimensional $P$ - and $S$-wave velocity structures beneath the Ryukyu arc, Tectonophysics, 369(3-4), 121-143, doi:10.1016/ S0040-1951(03)00172-0.

Nelson, K. D., et al. (1996), Partially molten middle crust beneath southern Tibet: Synthesis of Project INDEPTH results, Science, 274, 1684-1688, doi:10.1126/science.274.5293.1684

$\mathrm{Ni}$, J., and M. Barazangi (1984), Seismotectonics of the Himalayan collision zone: Geometry of the underthrusting Indian plate beneath the Himalaya, J. Geophys. Res., 89, 1147-1163, doi:10.1029/ JB089iB02p01147.

Owens, T. J., and G. Zandt (1997), Implications of crustal property variations for models of Tibetan Plateau evolution, Nature, 387, 37-43, doi: $10.1038 / 387037 \mathrm{a} 0$

Paige, C., and M. A. Saunders (1982), LSQR: An algorithm for sparse linear equations and sparse least squares, Trans. Math. Software, 8 43-71, doi:10.1145/355984.355989.

Pei, S., J. Zhao, Y. Sun, Z. Xu, S. Wang, H. Liu, C. Rowe, M. N. Toksoz, and X. Gao (2007), Upper mantle seismic velocities and anisotropy in China determined through $\mathrm{Pn}$ and $\mathrm{Sn}$ tomography, J. Geophys. Res. 112, B05312, doi:10.1029/2006JB004409.

Priestley, K., J. Jackson, and D. McKenzie (2008), Lithospheric structure and deep earthquakes beneath India, the Himalaya and southern Tibet, Geophys. J. Int., 172, 345-362, doi:10.1111/j.1365-246X.2007.03636.x.

Ren, Y., and Y. Shen (2008), Finite frequency tomography in southeastern Tibet: Evidence for the causal relationship between mantle lithosphere delamination and the north-south trending rifts, J. Geophys. Res., 113 , B10316, doi:10.1029/2008JB005615.

Saltzer, R. L., E. Stutzmann, and R. van der Hilst (2004), Poisson's ratio in the lower mantle beneath Alaska: Evidence for compositional heterogeneity, J. Geophys. Res., 109, B06301, doi:10.1029/2003JB002712.

Schulte-Pelkum, V., G. Monsalve, A. Sheehan, M. R. Pandey, S. Sapkota, R. Bilham, and F. Wu (2005), Imaging the Indian subcontinent beneath the Himalaya, Nature, 435, 1222-1225, doi:10.1038/nature03678.

Shapiro, N. M., and M. H. Ritzwoller (2002), Monte-Carlo inversion for a global shear-velocity model of the crust and upper mantle, Geophys. J. Int., 151, 88-105, doi:10.1046/j.1365-246X.2002.01742.x.

Shelton, G. L., J. Tullis, and T. Tullis (1981), Experimental high temperature and high pressure faults, Geophys. Res. Lett., 8, 55-58, doi:10.1029/ GL008i001p00055.

Sol, S., et al. (2007), Geodynamics of the southern Tibetan Plateau from seismic anisotropy and geodesy, Geology, 35, 563-566, doi:10.1130/ G23408A.1.

Spain, M., and A. Hirn (1997), Seismic structure and evidence for eclogitization during the Himalayan convergence, Tectonophysics, 273, 1-16, doi:10.1016/S0040-1951(96)00285-5.

Sun, Y., L. Xu, S. Kuleli, F. D. Morgan, and M. N. Toksoz (2004), Adaptive moving window method for 3-D $P$-velocity tomography and its application in China, Bull. Seismol. Soc. Am., 94, 740-746, doi:10.1785/0120030129.

Sun, Y., M. N. Toksoz, S. Pei, and F. D. Morgan (2008), The layered shear wave velocity structure of the crust and uppermost mantle in China, Bull. Seismol. Soc. Am., 98, 746-755, doi:10.1785/0120050222.

Tapponnier, P., J. L. Mercier, R. Armijo, T. Han, and J. Zhao (1981), Field evidence for active normal faulting in Tibet, Nature, 294, 410-414, doi:10.1038/294410a0.

Taylor, M., A. Yin, F. J. Ryerson, P. Kapp, and L. Ding (2003), Conjugate strike-slip faulting along the Bangong-Nujiang suture zone accommodates coeval east-west extension and north-south shortening in the interior of the Tibetan Plateau, Tectonics, 22(4), 1044, doi:10.1029/ 2002 TC001361.

Tilmann, F., J. Ni, and I. S. Team (2003), Seismic imaging of the downwelling Indian lithosphere beneath central Tibet, Science, 300, 14241427, doi:10.1126/science. 1082777.

VanDecar, J. C., and R. S. Crosson (1990), Determination of the teleseismic relative phase arrival times using multi-channel cross-correlation and least squares, Bull. Seismol. Soc. Am., 80, 150-169.

Velasco, A. A., V. L. Gee, C. Rowe, D. Grujic, L. S. Hollister, D. Hernandez, K. C. Miller, T. Tobgay, M. Fort, and S. Harder (2007), Using small, temporary seismic networks for investigating tectonic deformation: Brittle deformation and evidence for strike-slip faulting in Bhutan, Seismol. Res. Lett., 78, 446-453, doi:10.1785/gssrl.78.4.446.

Willett, S. D., and C. Beaumont (1994), Subduction of Asian lithospheric mantle beneath Tibet inferred from models of continental collision, Nature, 369, 642-645, doi:10.1038/369642a0. 
Williams, H., S. Turner, S. Kelley, and N. Harris (2001), Age and composition of dikes in Southern Tibet: New constraints on the timing of eastwest extension and its relationship to postcollisional volcanism, Geology, 29(4), 339-342, doi:10.1130/0091-7613(2001)029<0339:AACODI >2.0. $\mathrm{CO} ; 2$.

Wittlinger, G., V. Farra, G. Hetenyi, J. Vergne, and J. Nabelek (2009), Seismic velocities in Southern Tibet lower crust: A receiver function approach for eclogite detection, Geophys. J. Int., 177, 1037-1049, doi:10.1111/j.1365-246X.2008.04084.x.

Yang, T., and Y. Shen (2006), Frequency-dependent crustal correction for finite-frequency seismic tomography, Bull. Seismol. Soc. Am., 96, 24412448, doi:10.1785/0120060038.

Yin, A. (2000), Mode of Cenozoic east-west extension in Tibet suggesting a common origin of rifts in Asia during the Indo-Asian collision, J. Geophys. Res., 105, 21,745-21,759, doi:10.1029/2000JB900168.

Yin, A. (2006), Cenozoic tectonic evolution of the Himalayan orogen as constrained by along-strike variation of structural geometry, exhumation history, and foreland sedimentation, Earth Sci. Rev., 76, 1-131, doi:10.1016/j.earscirev.2005.05.004.

Yin, A., and T. M. Harrison (2000), Geologic evolution of the HimalayanTibetan orogen, Annu. Rev. Earth Planet. Sci., 28, 211-280, doi:10.1146/ annurev.earth.28.1.211.
Zhang, L. F., S. G. Song, J. G. Liou, Y. L. Ai, and X. P. Li (2005), Relict coesite exsolution in omphacite from western Tianshan eclogites, China, Am. Mineral., 90(1), 181-186, doi:10.2138/am.2005.1587.

Zhang, P. Z., et al. (2004), Continuous deformation of the Tibetan Plateau from global positioning system data, Geology, 32(9), 809-812, doi:10.1130/G20554.1.

Zhao, W., and W. J. Morgan (1985), Uplift of Tibetan Plateau, Tectonics, 4, 359-369, doi:10.1029/TC004i004p00359.

Zhao, W., and W. J. Morgan (1987), Injection of Indian crust into Tibetan lower crust: A two-dimensional finite element model study, Tectonics, 6 , 489-504, doi:10.1029/TC006i004p00489.

Zhou, H. W., and M. A. Murphy (2005), Tomographic evidence for wholesale underthrusting of India beneath the entire Tibetan Plateau, J. Asian Earth Sci., 25, 445-457, doi:10.1016/j.jseaes.2004.04.007.

Zhu, L., and D. V. Helmberger (1996), Intermediate depth earthquakes beneath the India-Tibet collision zone, Geophys. Res. Lett., 23, 435438, doi:10.1029/96GL00385.

Y. J. Chen and X. Liang, Institute of Theoretical and Applied Geophysics, School of Earth and Space Sciences, Peking University, Beijing 100871, China. (johnyc@pku.edu.cn)

Y. Ren and Y. Shen, Graduate School of Oceanography, University of Rhode Island, Kingston, RI 02882, USA. 